\title{
Impact of North Atlantic SST and Tibetan Plateau forcing on seasonal transition of springtime South Asian monsoon circulation
}

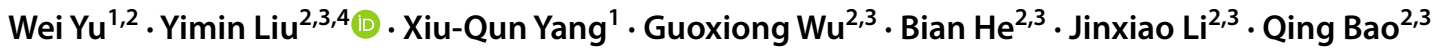

Received: 3 March 2020 / Accepted: 6 October 2020 / Published online: 16 October 2020

(c) The Author(s) 2020

\begin{abstract}
The South Asian circulation and precipitation in spring shows a clear seasonal transition and interannual variation. We investigate how the North Atlantic sea surface temperature (SST) and Tibetan Plateau (TP) forcing affect this seasonal transition over South Asia on interannual timescale. Our results suggest that North Atlantic SST can affect the seasonal transition of South Asian monsoon via TP forcing in spring. The positive tripole pattern of North Atlantic SST anomaly during winter-spring can trigger a steady downstream Rossby wave train with cyclonic circulation over the southwestern TP. This forms a spring dipole mode of surface sensible heating and $10 \mathrm{~m}$ winds over the plateau, with a westerly (easterly) flow and positive (negative) surface sensible heating over its southern (northern) regions. A distinct land-air coupling configuration in May is then generated on the southwestern TP via such a positive TP dipole mode, which consists of anomalous positive precipitation, negative surface sensible heating and a baroclinic circulation structure with cyclonic circulation in the mid- to upper troposphere and a shallow anticyclonic circulation in the lower layer. The anticyclonic circulation is opposite to the summertime monsoon circulation. It weakens the cross-equatorial flow and water vapor transport to the South Arabian Sea and Bay of Bengal, resulting in in-situ precipitation reduction. Consequently, the seasonal transition in circulation over South Asia from winter to summer is delayed.
\end{abstract}

Keywords Interannual variability $\cdot$ North Atlantic SST $\cdot$ Tibetan Plateau dipole mode $\cdot$ Land-air coupling mode $\cdot$ Seasonal transition over South Asia

Electronic supplementary material The online version of this article (https://doi.org/10.1007/s00382-020-05491-0) contains supplementary material, which is available to authorized users.

Yimin Liu

lym@lasg.iap.ac.cn

1 China Meteorological Administration-Nanjing University Joint Laboratory for Climate Prediction Studies,

School of Atmospheric Sciences, Nanjing University, Nanjing 210023, Jiangsu, China

2 State Key Laboratory of Numerical Modeling for Atmospheric Sciences and Geophysical Fluid Dynamics, Institute of Atmospheric Physics, Chinese Academy of Sciences, Beijing 100029, China

3 University of Chinese Academy of Sciences, Beijing 100049, China

4 Chinese Academy of Sciences Center for Excellence in Tibetan Plateau Earth Sciences, Beijing 100101, China

\section{Introduction}

In South Asia, the seasonal transition features as the onset of the monsoon associated with strong rainfall, which is usually considered to be a consequence of the atmospheric circulation response to the seasonal transition of the land-sea thermal contrast induced by the annual cycle of solar radiation (Webster et al. 1998). The concept of a "monsoon year" was proposed to highlight the fact that May is a seasonal transition month (Yasunari 1991). It is during early May that the Bay of Bengal (BOB) summer monsoon builds up and monsoon precipitation starts to develop in South Asia (Wang and LinHo 2002; Liang et al. 2005; Li and Zhang 2009; Wu et al. 2012). BOB monsoon is followed by the South China Sea monsoon, the Indian monsoon and the Asian-Pacific monsoon (Wu and Zhang 1998; Wu and Wang 2001; LinHo and Wang 2002; Ding and Chan 2005; Wang et al. 2004, 2009; Shin and Huang; 2016). From April to May, precipitation is significantly enhanced over the BOB and South Arabian Sea (SAS) (Deng et al. 2016). This increases the probability 
of flooding in the surrounding countries (e.g., Bangladesh, India, Burma and China), which may result in massive losses to agriculture and the economy (Gadgil et al. 2004; Webster and Hoyos 2004; Chen et al. 2006). The intense release of condensational latent heat associated with deep convection modulates the atmospheric circulation by triggering atmospheric waves (Wang 1988; Wang and Li 1994; Xie et al. 2009; Shin et al. 2019).

The seasonal transition and precipitation in May over the BOB and SAS show a significant interannual variability (Deng et al. 2016). Extensive researches have been conducted in exploring the factors affecting the interannual variability of the seasonal transition and precipitation over the SAS and BOB regions. These include the El Niño-Southern Oscillation (ENSO) (Mao and Wu 2007; Deng et al. 2016; Wang et al. 2017), the interannual variability of the local sea surface temperature (SST) (Jiang and Li 2011; Yu et al. 2012) and the timing of the South Asian High (SAH) establishment over the Indochina Peninsula (Wang and Guo 2012). In addition to these signals of tropical origin, the influence of the Europe-West Asia teleconnection from high latitudes has also been considered (Deng et al. 2016).

The TP which is located in the subtropics plays an important role in the regional and global climate as a result of its high mean elevation of $4 \mathrm{~km}$, huge size of greater than $2.5 \times 10^{6} \mathrm{~km}^{2}$ and variety of complex landscapes (Yanai and Wu 2006; Wu and Liu 2016). The dynamical and thermodynamical status over the elevated TP is a prominent source of atmospheric forcing in the subtropics, the so-called TP forcing. The TP forcing can modulate the atmospheric circulation over the whole globe (Duan and Wu 2005; Liu et al. 2007, 2020; Wu et al. 1997, 2007; Tamura and Koike 2010; Wang et al. 2018a, b). Besides the studies of the TP influence on the mean circulation and climate, the influence of TP thermal forcing on interannual variation of the Asian summer monsoon has also been well addressed (Zhao and Chen 2001; Wang et al. 2008; Lau and Kim 2018). There is a significant positive correlation between the intensity of spring (March, April, and May)—summer TP heat source and summer monsoon precipitation in the Yangtze River valley and a negative correlation in southern and northern China (Zhao and Chen 2001; Hsu and Liu 2003; Cui et al. 2015). The strong spring surface sensible heating $(\mathrm{SH})$ over the central-western TP can lead to an early onset of the Indian summer monsoon (Zhang et al. 2015).

Surface $S H$ over the TP is the dominant source of diabatic heating and reaches its maximum during the boreal spring (Yeh and Gao 1979; Liu et al. 2015; Duan et al. 2017; Zhao et al. 2018; Chen et al. 2019). The positive surface $S H$ anomaly over the TP generates negative vorticity anomaly at higher levels, which influences the atmospheric circulation across the northern hemisphere by triggering Rossby wave trains (Wu et al. 1996, 2015, 2016; Liu et al. 2017). Most previous studies generally used a prescribed or area-averaged $\mathrm{SH}$ over the TP to investigate its impact on climate $\mathrm{Wu}$ and Zhang 1998; Duan et al. 2011; Liu et al. 2007, 2012). A recent study based on station data indicated that the first leading empirical orthogonal function (EOF) mode of spring and summer $\mathrm{SH}$ over the TP on an interannual timescale has an out-of-phase distribution between the south and north (Yu et al. 2018b). It is unclear whether there are different impacts on the seasonal transition over South Asia among the different leading modes of the TP SH. More importantly, $\mathrm{SH}$ over the TP is not only the forcing source of atmospheric circulation, but is also a result of the atmospheric circulation. Therefore determining the mechanisms involved in the generation of the springtime $S H$ over the TP is challenging and requires further investigation.

The North Atlantic Oscillation (NAO) is the prominent atmospheric mode at mid- and high latitudes in boreal winter (Cayan 1992a, b). The local latent and sensible heat fluxes associated with the NAO can trigger a tripole pattern of SST anomaly (SSTA) in the North Atlantic in winter, which usually persists into the spring or even summer (Cayan 1992a, b; Deser and Timlin 1997; Czaja and Frankignoul 2002; Herceg-Bulić and Kucharski 2014; Zheng et al. 2016). A significant positive feedback exists between this tripole SSTA pattern and the NAO (Watanabe and Kimoto 2000; Pan 2005). It has been reported that North Atlantic SST (NASST) produces a memory in the ocean, allowing winter-spring NAO to affect the Indian summer monsoon and precipitation in the surrounding regions (Srivastava et al. 2002; Goswami et al. 2006). However, because there is a deep layer of easterly winds in the tropics that Rossby waves cannot penetrate, it is unclear how the winter-spring NASST in high latitudes related to the NAO can directly or indirectly affect the seasonal transition of circulation and precipitation over South Asia in the tropics.

There is a clear impact of the winter-spring NASST/NAO on the spring atmospheric circulation and surface heating over the TP (Yu and Zhou 2004; Li et al. 2005, 2008; Cui et al. 2015; Wang et al. 2019). Li et al. (2005) showed that during positive NAO phases in winter the westerly flow is enhanced and can induce an abnormal ascending motion and the formation of mid-tropospheric stratiform clouds over the TP. This results in the decrease of surface air temperature over the TP in March through a positive cloud-temperature feedback. Cui et al. (2015) demonstrated that a steady downstream Rossby wave train stretching from North Atlantic to the TP was stimulated by the tripole NASST/NAO in early spring, which intensifies the spring westerly jet and $\mathrm{SH}$ over the TP.

In view of the importance of $S H$ over the TP on the spring circulation over South Asia and its close connection with the preceding NASST, it is reasonable to infer that the interannual variability in the seasonal transition and precipitation 
over South Asia may be influenced by the winter-spring NASST through the modulation of TP forcing in spring. This study verifies this hypothesis by addressing the following questions. (1) Can the winter-spring NASST anomaly directly affect the seasonal transition and associated precipitation over South Asia? (2) What is the role of spring TP forcing in relaying the influence of the NASST on the circulation over South Asia? (3) How does the spring TP forcing affect the seasonal transition and associated precipitation over South Asia? Our focus is on how the NASST and the TP forcing influence the seasonal transition of circulation and precipitation over South Asia, instead of the detailed evolution of the onset of the South Asian summer monsoon (SASM).

The remainder of this paper is arranged as follows. Section 2 describes the data, methods and numerical model used for the study. Section 3 presents the spring climate features over South Asia and the TP. Section 4 investigates the possible impact of the winter-spring NASST on TP forcing in spring and their combined effect on the spring climate over South Asia. Section 5 discusses the physics of influence of the NASST on TP forcing in spring based on data diagnosis and numerical simulations. The physical mechanisms of influence of spring TP forcing on the seasonal transition of the SASM and the associated circulation and precipitation over South Asia are investigated in Sect. 6. A summary and discussion are presented in Sect. 7.

\section{Data, methods and model}

\subsection{Data}

Quality-controlled surface meteorological observations are obtained from 73 stations on the TP, which were derived from the China Meteorology Administration (https://data. cma.cn/). The variables used for this study include the surface air temperature $\left(T_{\mathrm{a}}\right)$, the $10 \mathrm{~m}$ wind speed $\left(V_{10}\right)$ and the land surface temperature $\left(T_{\mathrm{s}}\right)$; these measurements are made four times each day. Because reanalysis datasets are subject to uncertainties, we selected three different types of monthly atmospheric reanalysis data for comparison: (1) the Modern-Era Retrospective Analysis for Research and Applications Version 2 (MERRA-2) dataset with a horizontal resolution of $0.625^{\circ} \times 0.5^{\circ}$ and 42 vertical pressure levels (https://gmao.gsfc.nasa.gov/GMAO_ products/reanalysis_products.php; Gelaro et al. 2017); (2) the Japanese 55-year Reanalysis (JRA-55) dataset with a horizontal resolution of $1.25^{\circ} \times 1.25^{\circ}$ (https://jra.kisho u.go.jp/JRA-55/index_en.html; Kobayashi et al. 2015); and (3) the European Centre for Medium-Range Weather Forecasts Interim (ERA-Interim) reanalysis dataset with a horizontal resolution of $0.75^{\circ} \times 0.75^{\circ}$ (https://apps.ecmwf .int/datasets; Dee et al. 2011). Monthly precipitation data were provided by version 2.3 of the Global Precipitation Climatology Project (GPCP) with a horizontal resolution of $2.5^{\circ} \times 2.5^{\circ}$ (https://www.esrl.noaa.gov/psd/data/gridd ed/data.gpcp.html; Adler et al. 2003). Monthly SST data were provided by the Hadley Centre Sea Ice and Sea Surface Temperature Data Set Version 1 (HadISST1) with a horizontal resolution of $1^{\circ} \times 1^{\circ}$ (https://www.metoffice. gov.uk/hadobs/hadisst; Rayner et al. 2003).

All these datasets cover the time period 1980-2014. A 2-9 years bandpass Lanczos filter was applied to these datasets after the linear trends had been removed to extract the signals of interannual variability (Sun et al. 2019).

\subsection{Methods}

The bulk aerodynamic formula is employed to calculate the $S H$, which is defined as:

$S H=\rho C_{p} C_{H} V\left(T_{s}-T_{a}\right)$,

$\rho, C_{p}$ and $C_{H}$ are separately the air density, the specific heat of dry air at a constant pressure and the drag coefficient for heat (for details, see Duan and Wu 2008). $V$, $T_{s}$ and $T_{a}$ are derived from the local four times each day observations at all 73 stations over the TP. This equation has been widely used in studies related to the TP (Yeh and Gao 1979; Li and Yanai 1996; Duan and Wu 2008; Yang et al. 2011; Wang and Guo 2012).

Several statistical methods are utilized in this study, which includes EOF analysis, linear regression, correlation, partial correlation and composite analysis. To diagnose the generation and propagation of Rossby waves, the wave activity flux derived from Takaya and Nakamura (2001) is employed. We used the Niño3.4 index (areaaveraged SSTA over $5^{\circ} \mathrm{S}-5^{\circ} \mathrm{N}, 170^{\circ}-120^{\circ} \mathrm{W}$ ) to measure the strength of ENSO events. Spring is defined as the period from March to May.

The partial correlation is calculated based on the following formula:

$r_{12,3}=\frac{r_{12}-r_{13} r_{23}}{\sqrt{\left(1-r_{13}^{2}\right)\left(1-r_{23}^{2}\right)}}$,

$r_{12}$ is the correlation coefficient between variable 1 and variable $2, r_{13}$ and $r_{23}$ are similar with $r_{12} . r_{12,3}$ is the partial correlation coefficient between variable 1 and variable 2 with variable 3 removed (Zar 2010).

To evaluate the statistical significance of our results, the two-tailed Student's $t$-test is employed, among which the degree of effective freedom $N_{e}$ is defined as: 
$N_{e}=N_{o} \frac{1-r_{1} r_{2}}{1+r_{1} r_{2}}$,

$N_{o}$ illustrates the original sample size. $r_{1}$ and $r_{2}$ are separately the lag 1 auto-correlation coefficients of two series (Bretherton et al. 1999).

\subsection{Model}

We used version 2 of the finite-volume atmospheric model (FAMIL2) atmospheric general circulation model (AGCM), the latest generation AGCM of the State Key Laboratory of Numerical Modeling for Atmospheric Sciences and Geophysical Fluid Dynamics (LASG), Institute of Atmospheric Physics (IAP), Chinese Academy of Sciences (CAS) (Bao et al. 2019; Li et al. 2019). This is the atmospheric component of the climate system model CAS FGOALS-f2. We used the version with a horizontal resolution of C96 (about $100 \mathrm{~km}$ ) and 32 vertical levels extending from the surface to $1 \mathrm{hPa}$.

FAMIL2 uses a finite-volume dynamic core (Lin 2004) and a cubed-sphere grid system (Putman and Lin 2007). A resolving convective precipitation parameterization (@2017 FAMIL Development Team) is also used, in which the microphysical processes are calculated in the cumulus scheme for both shallow and deep convection (Lin et al. 1983; Harris and Lin 2014; Li et al. 2019). CAS FGOALSf2 participated in the Coupled Model Intercomparison Project Phase 6 (CMIP6). It showed a good performance in the simulation of precipitation over the TP and East Asia, the characteristics of the ENSO and the propagation of the Madden-Julian oscillation (Yu et al. 2018a; Bao et al. 2019; He et al. 2019; Li et al. 2019).

\section{Spring climate features over South Asia and the Tibetan Plateau}

\subsection{Features of circulation and precipitation over South Asia in late spring}

The most distinct feature of seasonal transition of boreal spring circulation over South Asia is the onset of the BOB summer monsoon. The easterly flow at lower levels dominates the SAS and central BOB in April (Fig. 1a). It abruptly changes to southwesterly in May (Fig. 1b), accompanied by a significant increase in precipitation over the BOB, SAS and Indochina Peninsula with the value above $3 \mathrm{~mm}^{\text {day }}{ }^{-1}$ (Fig. 1c).

The regions (BOB and SAS) with a significant increase in precipitation from April to May (red boxes in Fig. 1c) are coincident with the areas of strong interannual variability of precipitation in May (red boxes in Fig. 1b). The interannual standard deviation of precipitation over these regions in May is greater than $2 \mathrm{~mm} \mathrm{day}^{-1}$. This indicates that the seasonal transition of circulation and precipitation over South Asia in late spring is closely linked with the corresponding variability in May because the onset of the BOB summer monsoon usually occurs in early May. Therefore, we use the precipitation anomalies in May over South Asia to represent the anomalous seasonal transition of SASM (Xiang and Wang 2013). The precipitation anomalies in May over the SAS (area-averaged over $4^{\circ}-14^{\circ} \mathrm{N}, 57^{\circ}-75^{\circ} \mathrm{E}$ ) and the BOB (area-averaged over $8^{\circ}-26^{\circ} \mathrm{N}, 87^{\circ}-100^{\circ} \mathrm{E}$ ) regions (red boxes in Fig. 1b) are highly correlated (0.63, exceeding the $99 \%$ confidence level).

A seasonal transition index (STI) is defined as May precipitation anomalies averaged over the SAS and the BOB regions, as shown in two red boxes in Fig. 1b-d. A positive STI implies an earlier seasonal transition of SASM, whereas a negative STI implies a delayed seasonal transition of SASM.

Figure $1 \mathrm{~d}$ shows the regression pattern of precipitation in May against the STI. The SAS and BOB are occupied with notable positive precipitation anomalies, whereas remarkable negative precipitation anomalies occur over the southwestern TP and northwestern India. The correlation coefficient between May precipitation over southwestern TP (area-averaged over $27^{\circ}-37^{\circ} \mathrm{N}, 65^{\circ}-78^{\circ} \mathrm{E}$ ) and SAS is -0.39 (at $95 \%$ confidence level) and the correlation coefficient between May precipitation over southwestern TP and BOB in May is -0.76 (at $99 \%$ confidence level). These results suggest that the earlier seasonal transition in the SASM corresponds to more precipitation over the SAS and BOB and below-normal precipitation over the southwestern $\mathrm{TP}$, and vice versa.

\subsection{Features of surface sensible heating and wind over the Tibetan Plateau in spring}

Conventional observation stations are sparse over the TP, mainly due to the complex terrain, and therefore the estimation of the surface $S H$ distribution over the TP is still controversial. Previous studies have shown that the JRA-55 and ERA-Interim reanalysis datasets perform better in estimating the $S H$ over the TP (Zhu et al. 2012; Liu et al. 2015). Recently released MERRA-2 reanalysis dataset has also been used in climate research and performs better than the MERRA reanalysis dataset with respect to the water source, the land surface energy budget and the $2 \mathrm{~m}$ air temperature (Selkirk et al. 2015; Draper et al. 2018). We explore the discrepancies between the observations and the three reanalysis datasets through comparing the interannual variability of $\mathrm{SH}$ over the TP above $2000 \mathrm{~m}$. The spatial distribution of the first two EOFs based on both the observations and reanalysis dataset represent either a dipole between the southeastern 
(a) Apr precip (STD), uv 850hPa (climate mean)

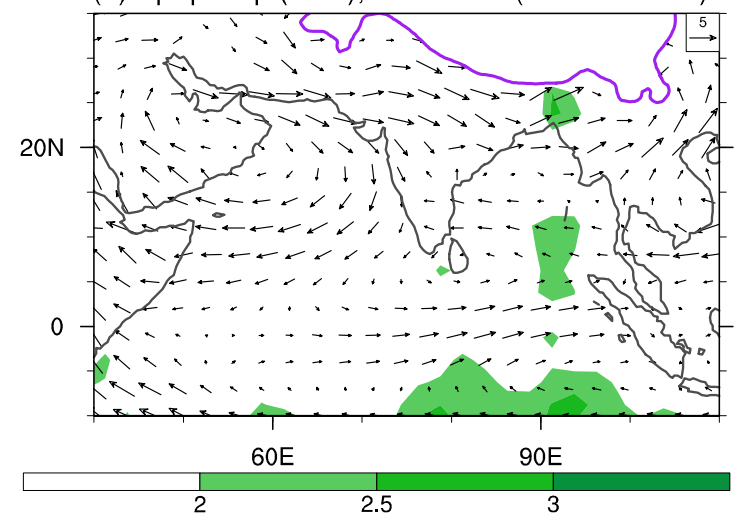

(c) May-Apr precip,uv $850 \mathrm{hPa}$ (climate mean)

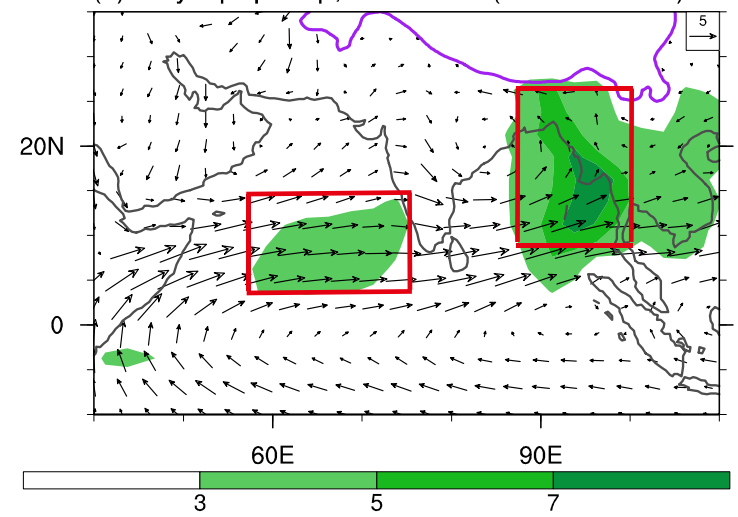

Fig. 1 Interannual standard deviation of precipitation (shading, $\mathrm{mm} \mathrm{day}{ }^{-1}$ ) and the climatological mean $850 \mathrm{hPa}$ wind field (vectors, $\mathrm{m} \mathrm{s}^{-1}$ ) in a April, and $\mathbf{b}$ May. $\mathbf{c}$ Differences in climatological mean precipitation (shading, $\mathrm{mm} \mathrm{day}^{-1}$ ) and $850 \mathrm{hPa}$ wind field (vectors, $\mathrm{m} \mathrm{s}^{-1}$ ) between May and April. d Regression pattern of precipitation $\left(\mathrm{mm} \mathrm{day}^{-1}\right)$ in May against the STI during 1980-2014. The two

and northwestern TP or a nearly uniform mode (Fig. S1). The dipole modes of $\mathrm{SH}$ over the TP extracted from these four datasets show a high consistency on the interannual time scale, whereas the uniform modes of $\mathrm{SH}$ are generally not consistent with each other (Fig. S2). Caution should therefore be taken when we use these $S H$ datasets.

According to Eq. (1), the factors $\left(T_{\mathrm{s}}-T_{\mathrm{a}}\right)$ and $V_{10}$ are the dominant elements determining the magnitude of $\mathrm{SH}$. On decadal timescale, $\left(T_{\mathrm{s}}-T_{\mathrm{a}}\right)$ presents a smaller change than $V_{10}$ (Yeh and Gao 1979; Liu et al. 2012). Regarding the interannual variability, Duan and $\mathrm{Wu}(2009)$ and $\mathrm{Yu}$ et al. (2018b) found that the contribution of $V_{10}$ to the variation in spring $S H$ over the TP is larger than that of $\left(T_{\mathrm{s}}-T_{\mathrm{a}}\right)$ based on partial correlation and multiple linear regression. It means that the interannual variation of spring $S H$ over the TP largely depends on the variation in $V_{10}$.

Figure 2 shows the first two leading EOF modes for the spring $V_{10}$ over the TP region above $2000 \mathrm{~m}$ based on the four datasets. The EOF1 of $V_{10}$ in spring represents a uniform mode (Fig. 2a, c, e, g), and the correlation coefficients

\section{(b) May precip (STD), uv 850hPa (climate mean)}

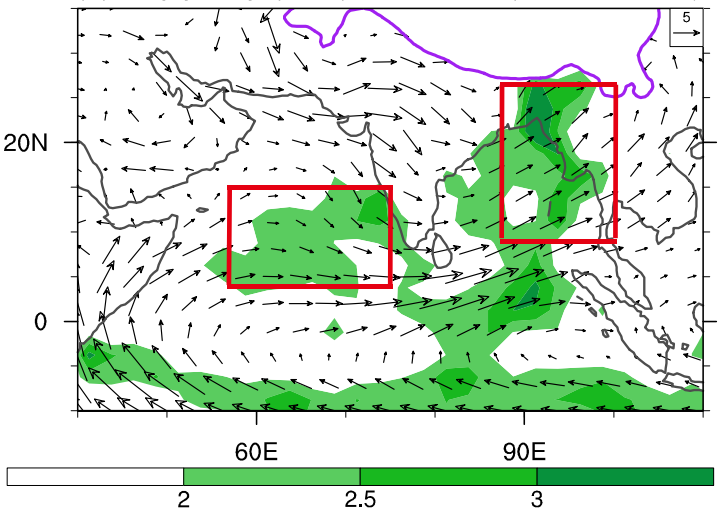

(d) STI vs May precip

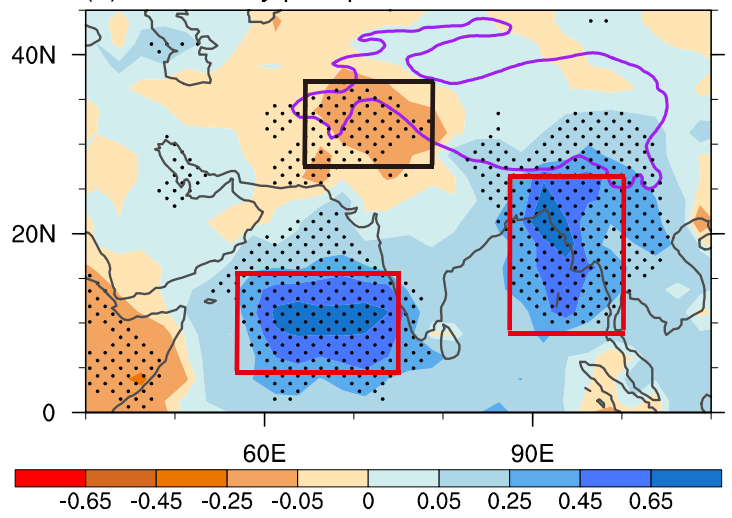

red boxes in $\mathbf{b}, \mathbf{c}, \mathbf{d}$ are the same and indicate the maximum center over the South Arabian Sea and Bay of Bengal. The black box in d indicates the maximum center over the southwestern Tibetan Plateau. The stippled areas in $\mathbf{d}$ denote values exceeding the $95 \%$ confidence level based on Student's $t$-test. The purple contour indicates the $2000 \mathrm{~m}$ topographic height

between PC1 of observation and PC1 of MERRA-2, JRA55 and ERA-Interim reanalysis datasets are $0.91,0.88$, and 0.90 , respectively (Fig. S3). The EOF2 represents a south-north dipole mode (Fig. 2b, d, f, h), and the correlation coefficients between PC2 of observation and PC2 of MERRA-2, JRA-55 and ERA-Interim reanalysis datasets are $0.82,0.67$, and 0.76 , respectively (Fig. S3). The correlation coefficients are all above the $99 \%$ confidence level, indicating that the interannual variations in $V_{10}$ over the TP derived from the four datasets are highly consistent and MERRA-2 dataset is most consistent with observation. Due to the deficiency of station data over the TP (especially in the western TP), the MERRA-2 dataset was selected for the subsequent analysis.

Considering the consistent variation in the uniform mode, we calculated the area-averaged $V_{10}$ over the TP region $\left(25^{\circ}-40^{\circ} \mathrm{N}, 70^{\circ}-105^{\circ} \mathrm{E}\right)$ above $2000 \mathrm{~m}$ and defined a surface wind index $\left(\mathrm{V}_{10} \mathrm{I} 1\right)$ to represent the temporal evolution of the uniform mode. The area-averaged difference in $V_{10}$ between the southern TP $\left(27^{\circ}-31^{\circ} \mathrm{N}\right.$, 


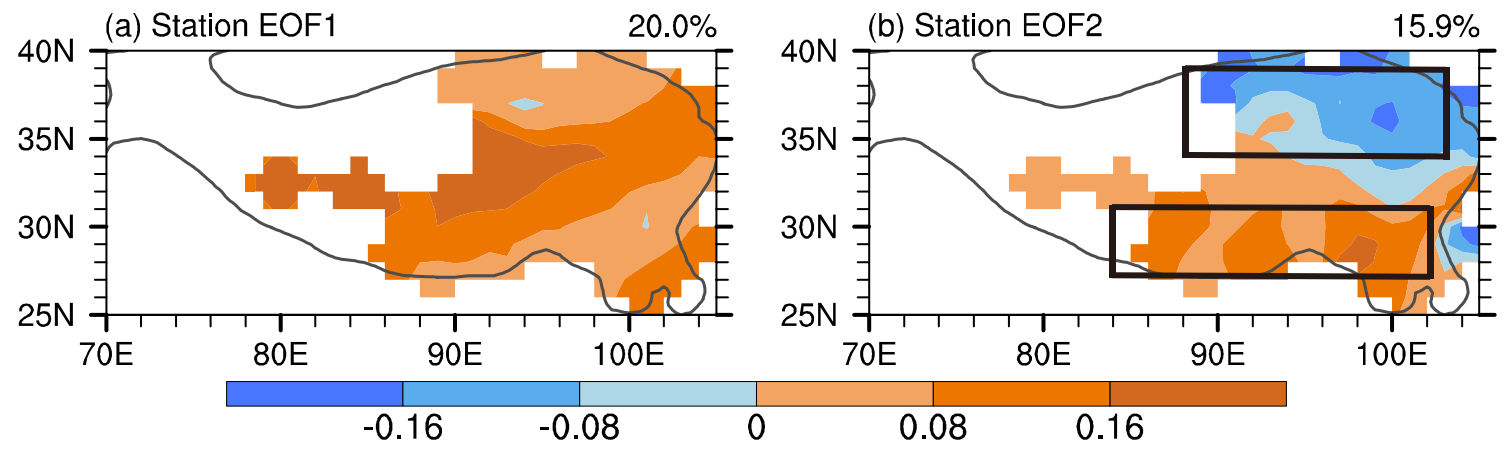

(c) MERRA-2 EOF1 $41.5 \%$

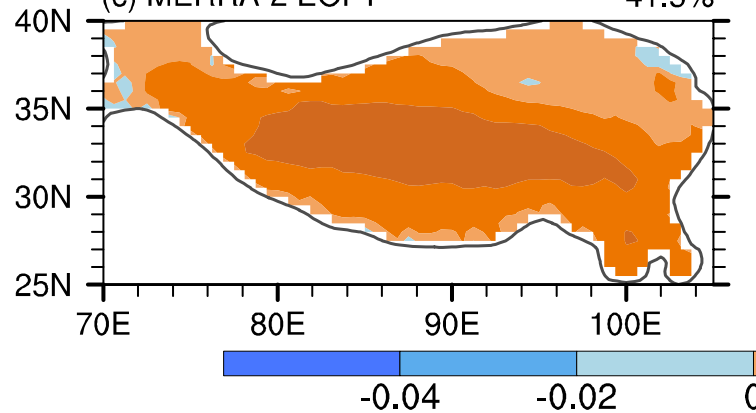

(d) MERRA-2 EOF2

$23.4 \%$
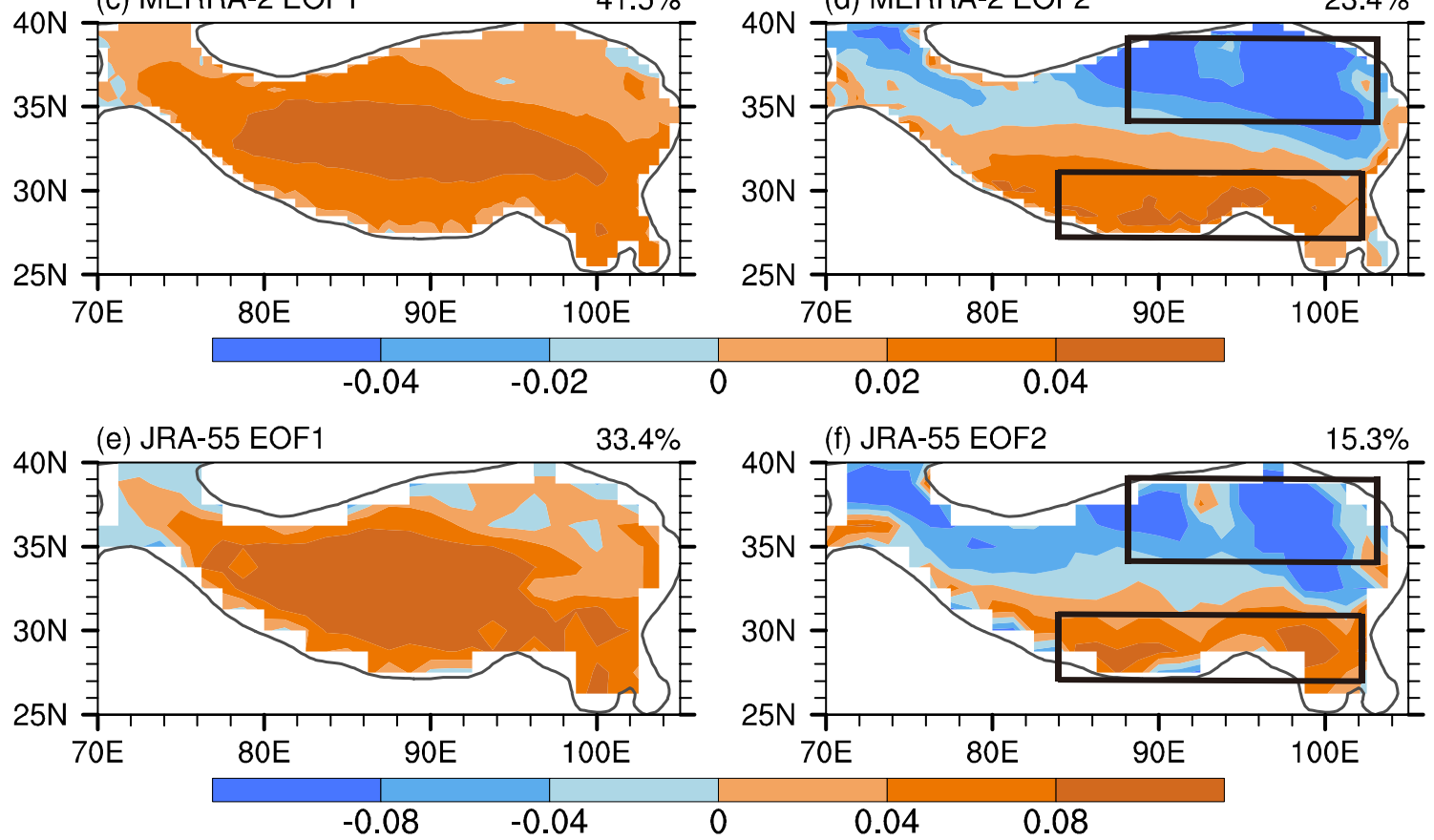

(g) ERA-Interim EOF1

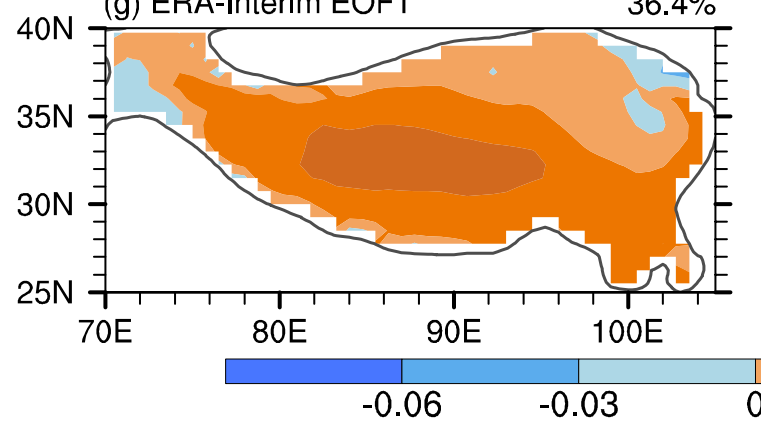

(h) ERA-Interim EOF2

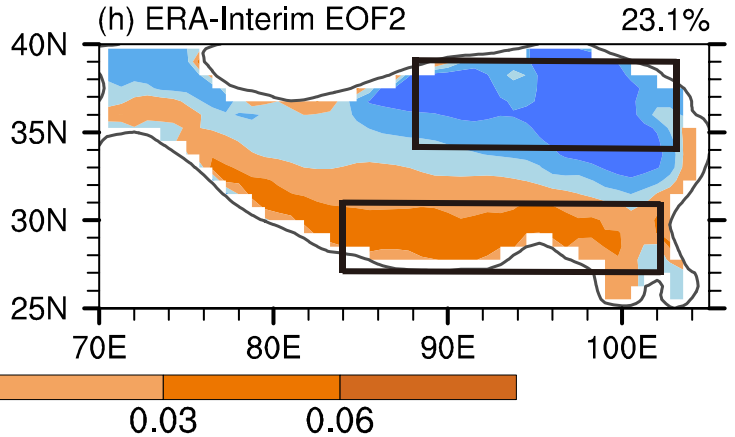

Fig. 2 Spatial patterns of the (left-hand column) first and (right-hand column) second EOF modes of spring $10 \mathrm{~m}$ wind speed over the Tibetan Plateau above $2000 \mathrm{~m}$ during 1980-2014 based on a, b station data, $\mathbf{c}, \mathbf{d}$ the MERRA-2 dataset, $\mathbf{e}, \mathbf{f}$ the JRA-55 dataset, and $\mathbf{g}, \mathbf{h}$ the ERA-Interim dataset. The value in the upper right is the explained variance of the mode. The gray contour indicates the $2000 \mathrm{~m}$ topographic height

extracted from the MERRA-2 dataset is 0.99 (0.94), significant at the $99 \%$ confidence level. Therefore $\mathrm{V}_{10} \mathrm{I} 1$ and $\mathrm{V}_{10} \mathrm{I} 2$ extracted from the MERRA-2 dataset were used to represent the uniform mode and dipole mode, respectively, of $V_{10}$ in spring over the TP. 
The relationship between the spring $V_{10}$ and surface $S H$ over the TP is also explored. It is obvious that during the positive $\mathrm{V}_{10} \mathrm{I} 1$ years, a positive $S H$ anomaly with the center located in the central TP, and a westerly anomaly of $V_{10}$ occurred over the TP (Fig. 3b) which enhanced the climatological mean $V_{10}$ (Fig. 3a). The correlation coefficient between $\mathrm{V}_{10} \mathrm{I} 1$ and the PC2 (PC1) of $S H$ uniform mode based on station data (the MERRA-2 dataset) is 0.65 (0.67), exceeding the $99 \%$ confidence level. This implies that the uniform mode of $V_{10}$ can well represent the uniform mode of $S H$ over the TP. As for the dipole mode, there is a

(a) Spring $\mathrm{SH}$,uv $10 \mathrm{~m}$ climate mean

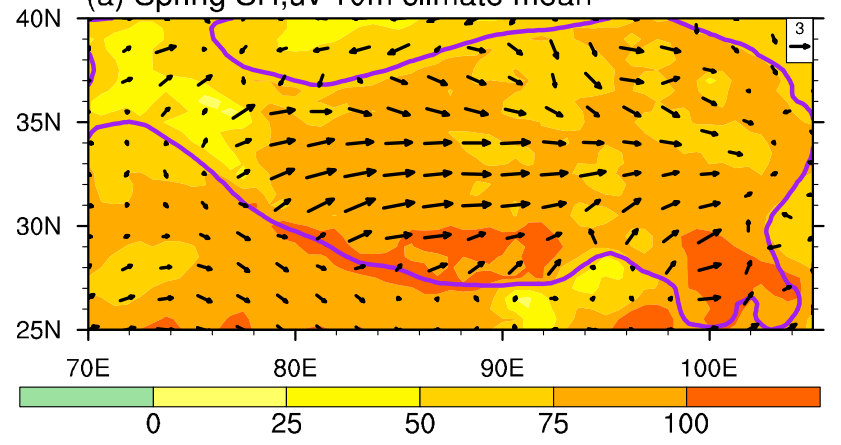

(b) $\mathrm{V}_{10} \mathrm{I}$ vs Spring $\mathrm{SH}$,uv $10 \mathrm{~m}$
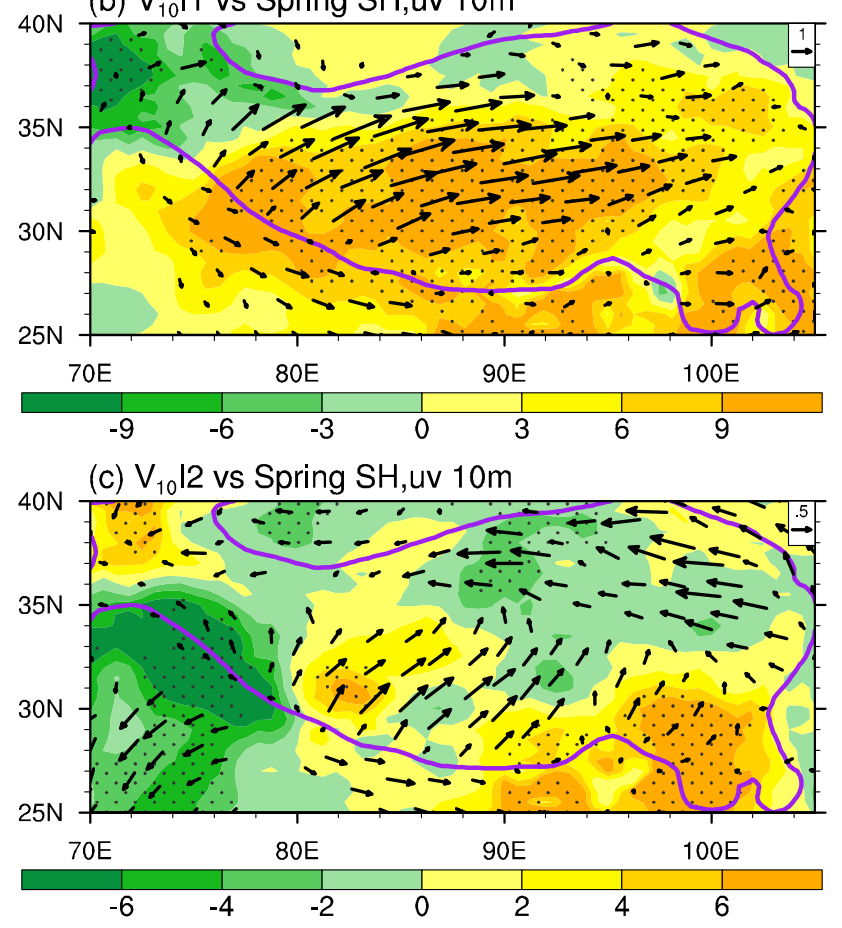

Fig. 3 a The climatological mean surface sensible heating (shading, $\mathrm{W} \mathrm{m}^{-2}$ ) and $10 \mathrm{~m}$ wind (vectors, $\mathrm{m} \mathrm{s}^{-1}$ ) in spring during 1980-2014. Regression patterns of spring surface sensible heating (shading, $\mathrm{W} \mathrm{m}{ }^{-2}$ ) and $10 \mathrm{~m}$ wind (vectors, $\mathrm{m} \mathrm{s}^{-1}$ ) against $\mathbf{b} \mathrm{V}_{10} \mathrm{I} 1$, and $\mathbf{c} \mathrm{V}_{10} \mathrm{I} 2$ during 1980-2014. The stippled areas in $\mathbf{b}$, $\mathbf{c}$ denote values exceeding the $95 \%$ confidence level based on Student's $t$-test. The black vectors in $\mathbf{b}, \mathbf{c}$ indicate values that are significant at the $95 \%$ confidence level. The purple contour indicates the $2000 \mathrm{~m}$ topographic height positive $S H$ anomaly over the southeastern TP and a negative $\mathrm{SH}$ anomaly over the western and northern TP during the positive $\mathrm{V}_{10} \mathrm{I} 2$ years (Fig. 3c). Correspondingly, the southwesterly anomaly of $V_{10}$ occupies the southern TP, while the easterly anomaly occurs in the northern TP (Fig. 3c), which enhanced (weakened) the climatological mean $V_{10}$ on the southern (northern) TP (Fig. 3a). The correlation coefficient between $\mathrm{V}_{10} \mathrm{I} 2$ and the PC1 (PC2) of $S H$ dipole mode based on station data (the MERRA-2 dataset) is 0.55 (0.39), which is significant at the $99 \%$ (95\%) confidence level. Therefore the dipole mode of $V_{10}$ can also be used to represent the dipole mode of $S H$ over the TP.

\section{Impacts of the Tibetan Plateau forcing in spring and North Atlantic SST on precipitation in South Asia}

\subsection{Impacts of spring Tibetan Plateau forcing on precipitation in South Asia}

Considering that the spring $S H$ anomaly over the TP and the associated circulations might influence precipitation over the SAS and BOB regions, we investigate the correlation pattern between $\mathrm{V}_{10} \mathrm{I} 1$ and precipitation in May (Fig. 4b). The correlation coefficient between $\mathrm{V}_{10} \mathrm{I} 1$ and STI is only -0.11 , indicating that the spring uniform $\mathrm{SH}$ and surface westerly winds over the TP might not be correlated with precipitation anomaly over the SAS and BOB in May. By contrast, the correlation pattern between $\mathrm{V}_{10} \mathrm{I} 2$ and precipitation in May presents significant negative correlations over the SAS, the northeastern BOB and the southeastern TP and positive correlations in the southwestern and northern TP (Fig. 4c). This pattern resembles the regression map of the precipitation anomaly against the STI (Fig. 1d), which indicates that the variation in precipitation over the SAS and BOB is of opposite sign to that over the southwestern TP. Such a close connection is also apparent from the time series of the normalized $\mathrm{V}_{10} \mathrm{I} 2$ (red solid curve in Fig. 4a) and negative STI (green solid curve in Fig. 4a). The correlation coefficient between $\mathrm{V}_{10} \mathrm{I} 2$ and STI is significant (-0.55). It is evident that the seasonal transition of the SASM and the associated precipitation anomaly over the SAS, BOB and southwestern TP in May are closely connected to the spring dipole modes of $S H$ and $V_{10}$ over the TP. The relationship of more precipitation and less $S H$ over the southwestern TP will be presented in Sect. 6.

Previous studies have shown that the ENSO is a dominant signal of the climate system in terms of interannual variability and is an important factor in regulating the interannual variation of precipitation over the SAS and BOB in spring (Mao and Wu 2007; Deng et al. 2016). Figure $4 \mathrm{~d}$ shows that warm ENSO events are highly correlated 
(a) Normalized

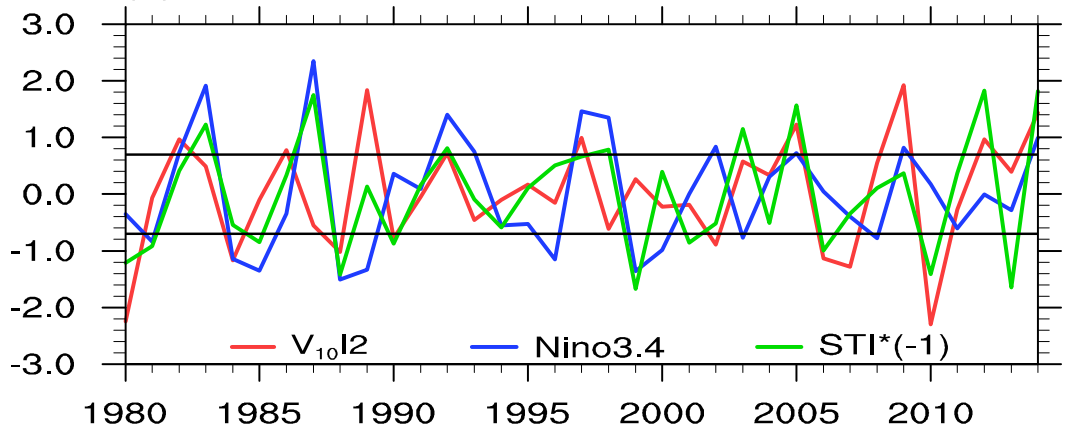

(b) $\mathrm{V}_{10} 11$ vs May precip

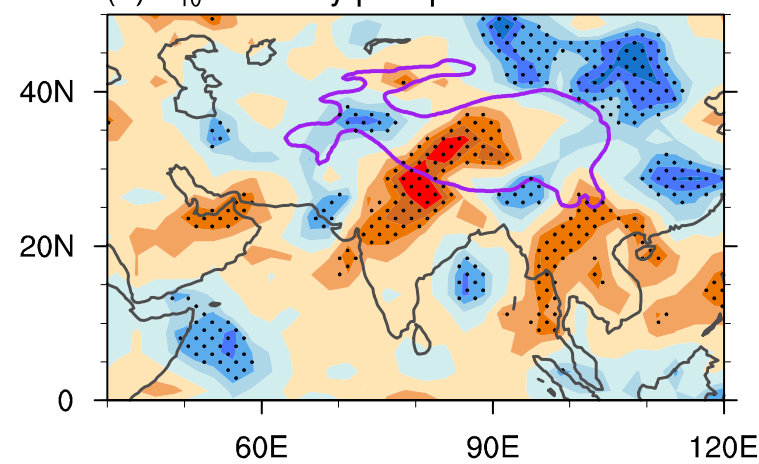

(d) Nino3.4 vs May precip

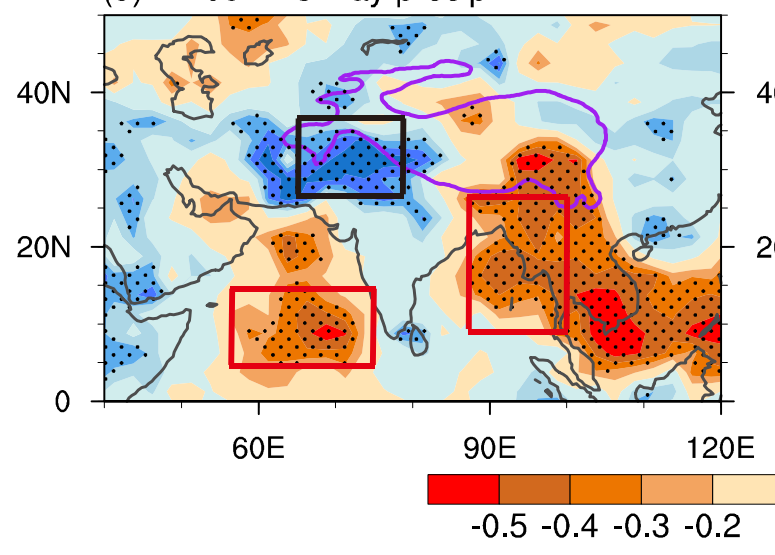

Fig. 4 a Time series of the normalized $\mathrm{V}_{10} \mathrm{I} 2$ (red solid curve), the May Niño3.4 index (blue solid curve) and the negative STI (green solid curve) during 1980-2014. The solid horizontal lines represent \pm 0.7 standard deviations. Correlation patterns between precipitation in May and $\mathbf{b} \mathrm{V}_{10} \mathrm{I} 1, \mathbf{c} \mathrm{V}_{10} \mathrm{I} 2$, and $\mathbf{d}$ the May Niño3.4 index.

with a distinct reduction in precipitation over the Arabian Sea, BOB, Indochina Peninsula and southeastern TP and a significant increase in precipitation over the southwestern TP in May. Similar features are also revealed by the correlation coefficient between the Niño3.4 index in May (blue solid curve in Fig. 4a) and the STI ( -0.52 , significant at the $99 \%$ confidence level). To explore whether the impacts of $S H$ over the TP and the $V_{10}$ dipole modes on the seasonal transition of the SASM and associated precipitation over the SAS and BOB are independent of the ENSO, (c) $\mathrm{V}_{10} \mathrm{I} 2$ vs May precip

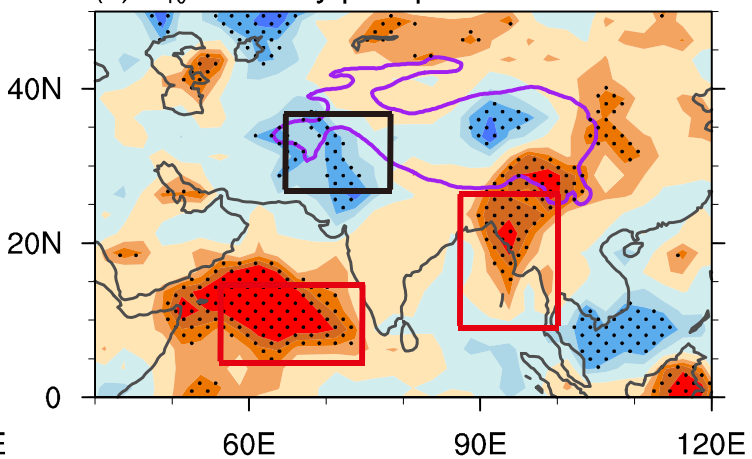

(e) $\mathrm{V}_{10} \mathrm{I2}$ (-Nino3.4) vs May precip

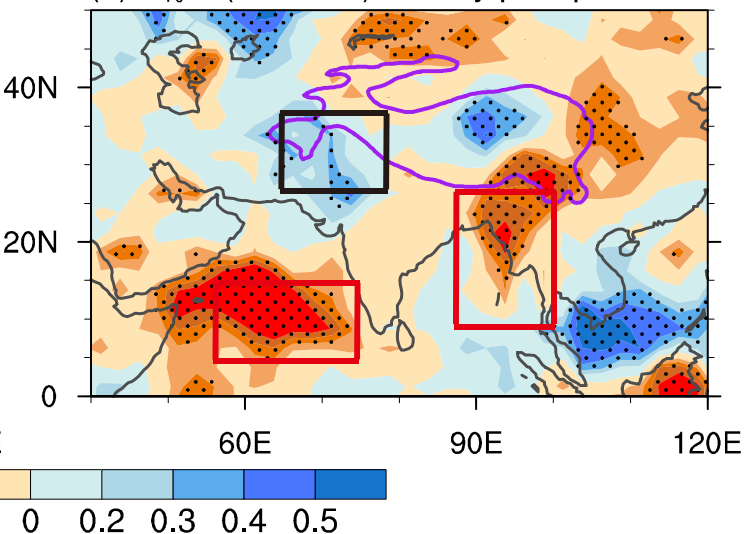

e Partial correlation pattern between precipitation in May and $\mathrm{V}_{10} \mathrm{I} 2$ with the May Niño3.4 index removed. The three boxes in $\mathbf{c}-\mathbf{e}$ are the same with Fig. 1d. The stippled areas in $\mathbf{b}-\mathbf{e}$ denote values exceeding the $90 \%$ confidence level based on Student's $t$-test. The purple contours in $\mathbf{b}-\mathbf{e}$ indicate the $2000 \mathrm{~m}$ topographic height

we calculated the partial correlation [Eq. (2)] between May precipitation and $\mathrm{V}_{10} \mathrm{I} 2$ with the May Niño3.4 signal removed (Fig. 4e). The spatial pattern is similar to the original correlation pattern between the $\mathrm{V}_{10} \mathrm{I} 2$ and May precipitation (Fig. 4c). The partial correlation coefficient between $\mathrm{V}_{10} \mathrm{I} 2$ and STI with removing the May Niño3.4 signal is -0.54 , nearly the same as the original correlation coefficient between $\mathrm{V}_{10} \mathrm{I} 2$ and STI $(-0.55)$. These results imply that the spring dipole modes of $S H$ and $V_{10}$ over the TP affect the seasonal transition of the SASM and the 
associated precipitation over the SAS, BOB and southwestern TP, which are independent of the ENSO.

\subsection{Impacts of the North Atlantic SST on precipitation in South Asia relayed by Tibetan Plateau forcing}

The NASST influences the variation of spring $S H$ and the westerly jet over the TP through triggering a steady downstream Rossby wave train, which extends from the North Atlantic to the TP (Cui et al. 2015). The correlation maps between $\mathrm{V}_{10} \mathrm{I} 2$ and the monthly mean NASST from the preceding January to May show that a significant tripole SSTA pattern exists over the North Atlantic (Fig. 5a-e). This pattern is sustained throughout the whole winter and spring as a result of the large heat content of the ocean and reaches a peak in March. The SSTA averaged over the warm core region in the central North Atlantic (the green box in Fig. $5 \mathrm{c} ; 30^{\circ}-40^{\circ} \mathrm{N}, 70^{\circ}-50^{\circ} \mathrm{W}$ ) is defined as the SSTW_C, the SSTA averaged over the cold core region in the subtropics (the southern red box in Fig. $5 \mathrm{c} ; 15^{\circ}-25^{\circ} \mathrm{N}$, $40^{\circ}-20^{\circ} \mathrm{W}$ ) is defined as the SSTC_S and in the subpolar area (the northern red box in Fig. $5 \mathrm{c} ; 50^{\circ}-60^{\circ} \mathrm{N}, 48^{\circ}-28^{\circ}$ W) is defined as the SSTC_N. Thus an SSTI is constructed to depict this tripole SSTA pattern:

SSTI $=$ 2SSTW_C - SSTC_S - SSTC_N

During the period from January to May, the SSTI of each month is highly correlated with the SSTIs of the other months (exceeding the $99 \%$ confidence level), except for the correlation coefficient between January and May ( 0.29 , significant at the $90 \%$ confidence level), which further confirms the strong persistence of the tripole SSTA pattern over the North Atlantic (Cayan 1992a, b; HercegBulić and Kucharski 2014). For convenience, we used the March SSTI to represent the North Atlantic tripole SSTA pattern during winter and spring. The correlation coefficient between SSTI in March and $\mathrm{V}_{10} \mathrm{I} 2$ is 0.57 , which (a) $\mathrm{V}_{10} 12$ vs Jan SST

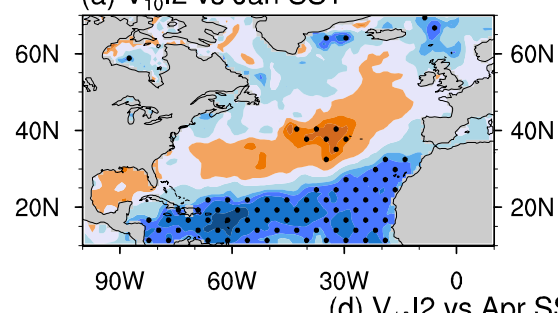

(b) $\mathrm{V}_{10} 12$ vs Feb SST

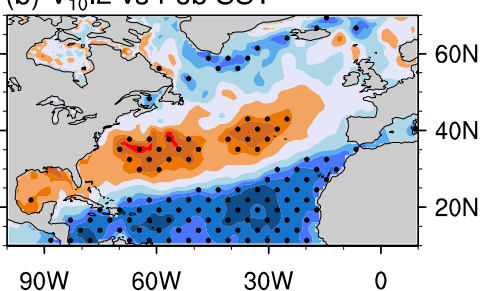

(c) $\mathrm{V}_{10} 12$ vs Mar SST

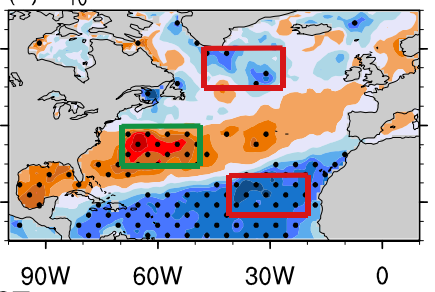

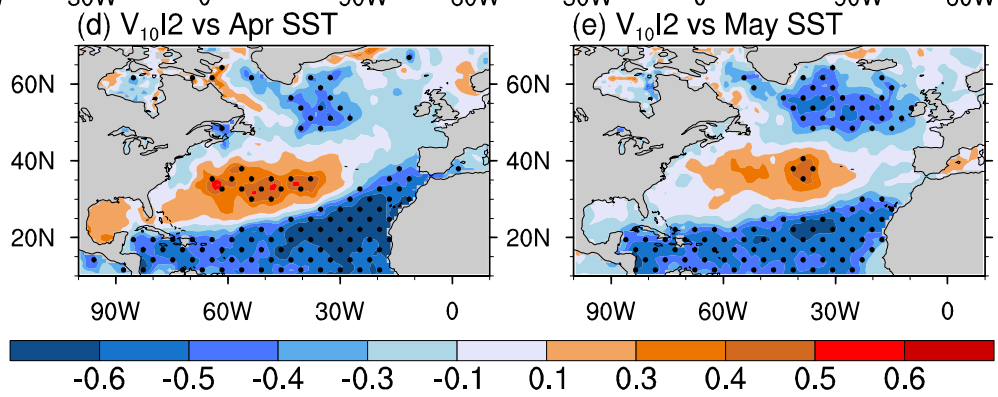

(g) Normalized
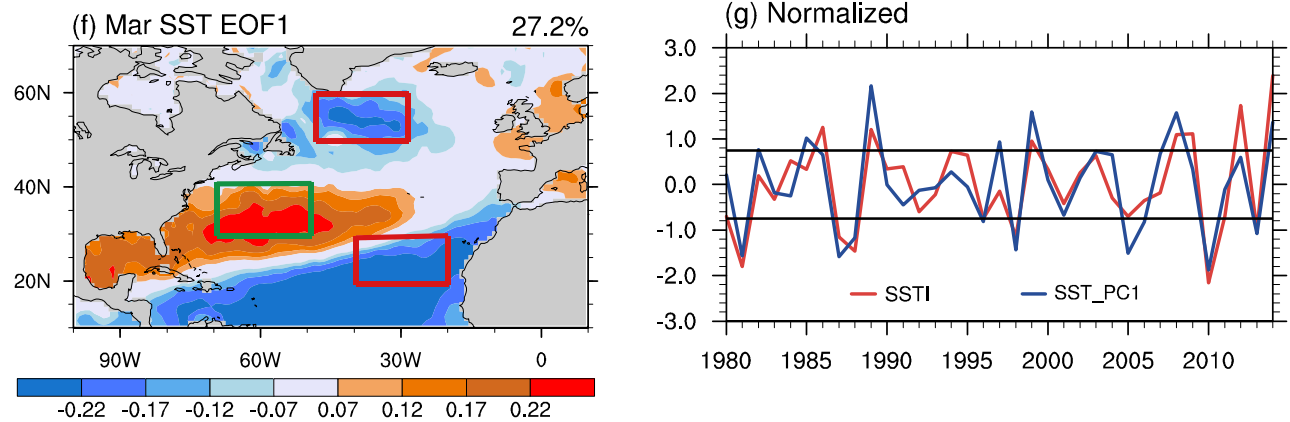

and the PC1 corresponding to the EOF1 of the North Atlantic SST in March (SST_PC1, blue solid curve). The three boxes in $\mathbf{c}$ and $\mathbf{f}$ are the same. The solid horizontal lines represent \pm 0.75 standard deviations. The stippled areas in a-e denote values exceeding the $95 \%$ confidence level based on Student's $t$-test 
is significant at $99 \%$ confidence level, implying that the winter-spring North Atlantic tripole SSTA pattern may induce the dipole modes of $S H$ and $V_{10}$ over the TP. As revealed by Cui et al. (2015), the leading mode (EOF1) of the interannual component of the NASST in March is a tripole pattern (Fig. 5f). This mode is similar to the correlation pattern between the NASST in March and $\mathrm{V}_{10} \mathrm{I} 2$ (Fig. 5c). The time series of the normalized March SSTI (red solid curve in Fig. 5g) and PC1 of the NASST in March (SST_PC1, blue solid curve in Fig. $5 \mathrm{~g}$ ) or the mean of February to April are all significantly correlated, with the correlation coefficient more than 0.80 .

We also examined the relationship between the winter-spring NASST and May precipitation over South Asia. The positive North Atlantic SSTA tripole pattern during winter-spring is significantly correlated with the negative precipitation anomaly over the SAS and northeastern BOB and the positive precipitation anomaly over the southwestern TP in May (Fig. 6a), similar to the distribution pattern illustrated in Fig. 1d. The correlation coefficient between the March SSTI and STI is -0.38 , which is significant at 95\% confidence level. However, the partial correlation coefficient between the March SSTI and the STI after removing $\mathrm{V}_{10} \mathrm{I} 2$ is only -0.03 , which suggests that there is no evident precipitation anomaly over the SAS, BOB and the southwestern TP (Fig. 6b). The above analysis indicates that the winter-spring North Atlantic tripole SSTA pattern might influence the seasonal transition over South Asia and the associated precipitation with the involvement of TP forcing in spring.

\section{Influence of North Atlantic SST on Tibetan Plateau forcing in spring}

\subsection{Data diagnosis}

The North Atlantic tripole SSTA pattern is closely coupled with the atmospheric NAO in winter. These SST anomalies can influence the atmospheric thermal structure via translating anomalous diabatic heating into the atmosphere. The March SSTI regressed SST, surface air temperature $T_{\mathrm{a}}$, air temperature in the mid- to upper troposphere and atmospheric circulation in March are presented in Fig. 7. The spatial pattern of $T_{\mathrm{a}}$ (Fig. 7b) is similar to the SST pattern (Fig. 7a), indicating the significant thermal impact of the SST tripole on the surface air temperature which also features the tripole configuration over the North Atlantic. Subject to the thermal wind relation, a near surface strong easterly flow is located between the tropical cold pole and the subtropical warm pole, while a strong westerly flow is located between the subtropical warm pole and the subpolar cold pole (Fig. 7a, b). A unique anticyclone circulation is (a) SSTI vs May precip

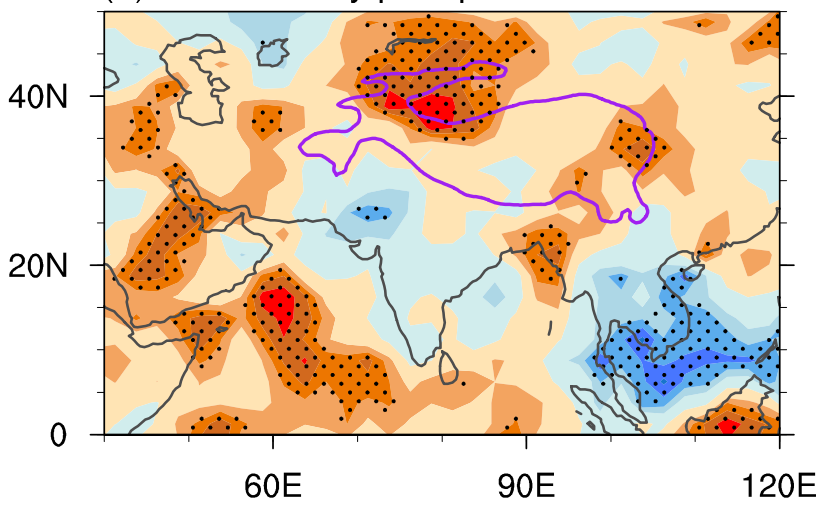

(b) SSTI (- $\left.\mathrm{V}_{10} \mathrm{I}\right)$ vs May precip

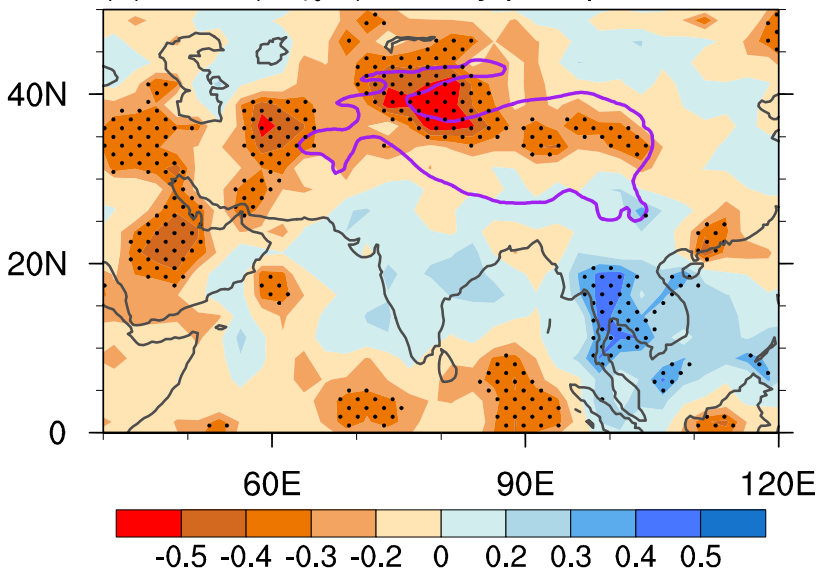

Fig. 6 a Spatial distribution of correlation between May precipitation and March SSTI. b Partial correlation pattern between May precipitation and March SSTI with $\mathrm{V}_{10} \mathrm{I} 2$ removed. The stippled areas denote values exceeding the $90 \%$ confidence level based on Student's $t$-test. The purple contour indicates the $2000 \mathrm{~m}$ topographic height

thus forced over the central North Atlantic. Due to the geostrophic advection limit in the extratropics (Smagorinsky 1953), this anticyclone circulation exists also in the mid- to upper troposphere accompanied with cyclonic circulations to its south and north (Fig. 7c, d), presenting an equivalent barotropic structure and forming a NAO like circulation over the North Atlantic.

To investigate the mechanism linking the winter-spring NAO/North Atlantic tripole SSTA pattern and the TP $V_{10}$ dipole mode, the spring atmospheric circulation and wave activity flux were regressed onto the March SSTI (Fig. 8). There is a typical Rossby wave train with four centers extending from the middle of the North Atlantic to the western TP at $500 \mathrm{hPa}$ (Fig. 8a). The four centers are located in the middle of the North Atlantic (marked A), the northern North Atlantic (marked B), western Europe (marked C) and the western TP (marked D), respectively. Geopotential height anomaly is positive in $\mathrm{A}$ and $\mathrm{C}$ and negative in $\mathrm{B}$ and D. This spatial distribution of geopotential height anomaly 


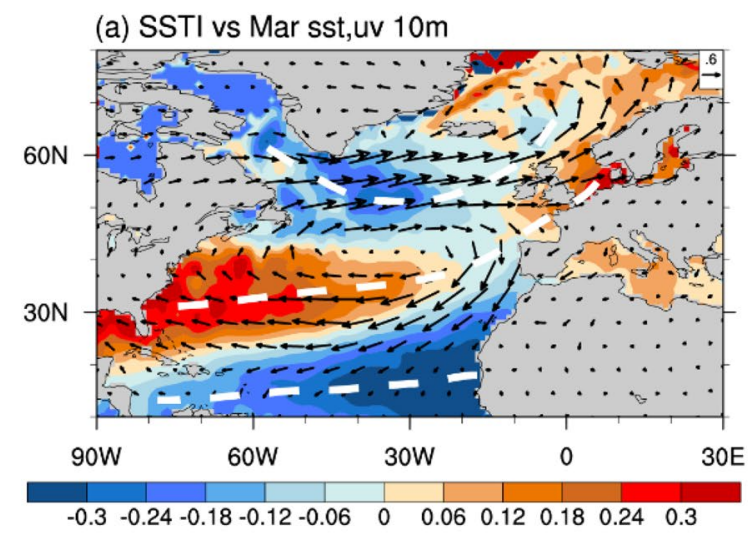

(c) SSTI vs Mar T $600 \mathrm{hPa}$,uv $500 \mathrm{hPa}$

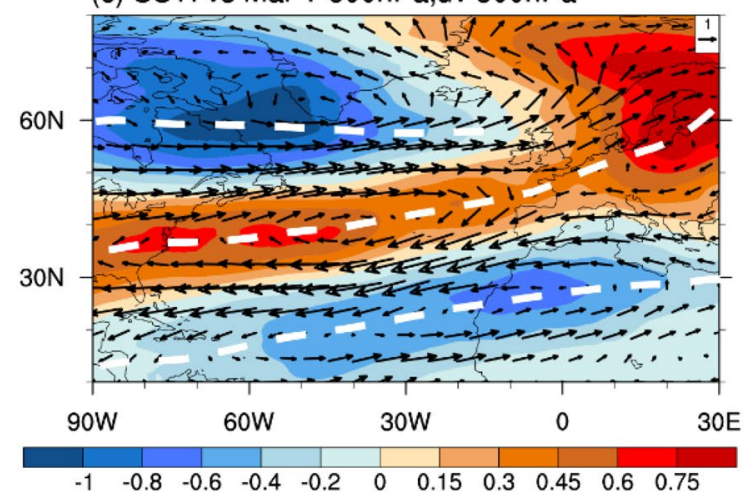

Fig. 7 Regression of March quantities against the March SSTI during 1980-2014. a SST (shading, ${ }^{\circ} \mathrm{C}$ ) and $10 \mathrm{~m}$ wind (vector, $\mathrm{m} \mathrm{s}^{-1}$ ). b Surface air temperature Ta (shading, ${ }^{\circ} \mathrm{C}$ ) and $925 \mathrm{hPa}$ wind (vector, $\mathrm{m} \mathrm{s}^{-1}$ ). c $600 \mathrm{hPa}$ temperature (shading, ${ }^{\circ} \mathrm{C}$ ) and $500 \mathrm{hPa}$ wind (vector, $\mathrm{m} \mathrm{s}^{-1}$ ). d $400 \mathrm{hPa}$ temperature (shading, ${ }^{\circ} \mathrm{C}$ ) and $300 \mathrm{hPa}$ wind (vector, $\mathrm{m} \mathrm{s}^{-1}$ ). The middle white dashed curve in $\mathbf{a}$ indicates the axis

refers to as the North Atlantic-Europe-TP (NaET) wave train in later study. Figure $8 \mathrm{~b}$ shows a zonal-vertical crosssection of geopotential height along the wave train linking A, B, C and D shown in Fig. 8a. An approximate equivalent barotropic structure appears from the middle of the North Atlantic to the western TP throughout almost the entire troposphere. A similar wave train is also found in the vorticity anomalies at $300 \mathrm{hPa}$ (Fig. 8c). Through diagnosing wave activity flux, we find that the wave energy originates from the region just above the warm center of the North Atlantic tripole SSTA pattern and propagates eastward to the western TP (Fig. 8c). An anomalous cyclonic circulation appears over the western TP, accompanied by a westerly anomaly over the southern TP and an easterly anomaly over the northern TP (Fig. 8b, d). The regressed surface wind pattern over the TP (Fig. 8e) is similar to the corresponding pattern at $500 \mathrm{hPa}$ and is indeed mimicking the dipole mode of $V_{10}$ as shown in Fig. 3c. This is because the average altitude of the TP exceeds $4000 \mathrm{~m}$, so that the dipole mode of surface wind $V_{10}$ over the TP (Figs. 3c, 8e) is consistent with the wind pattern at $500 \mathrm{hPa}$ (Fig. 8d). In short, the winter-spring

\section{(b) SSTI vs Mar Ta,uv $925 \mathrm{hPa}$}

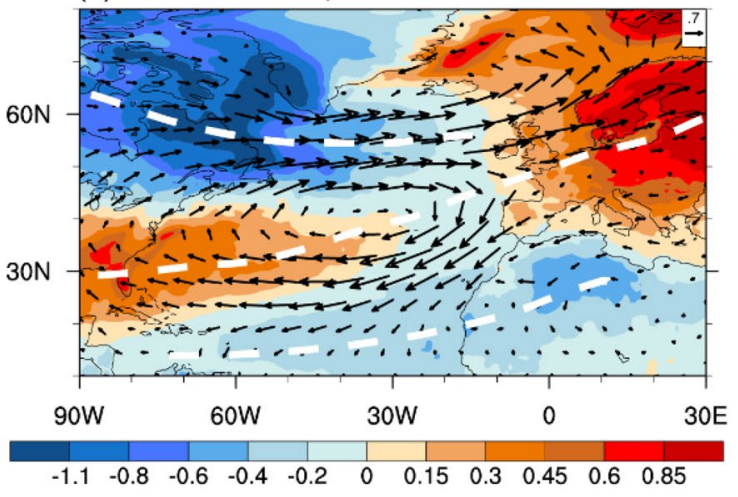

(d) SSTI vs Mar T $400 \mathrm{hPa}$,uv $300 \mathrm{hPa}$

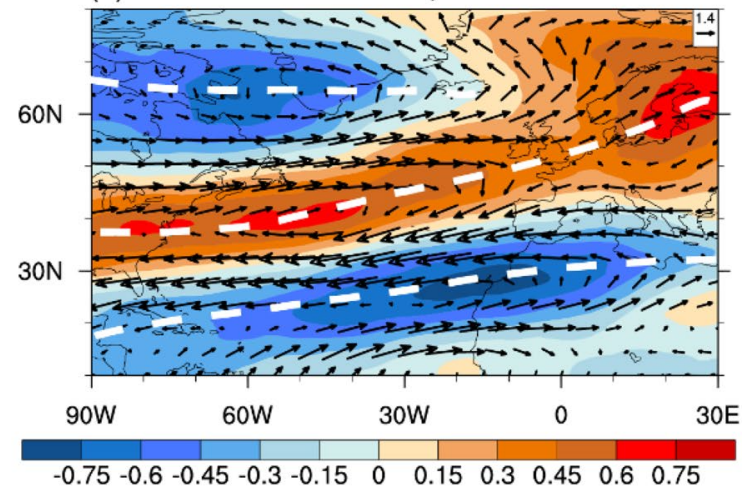

of the maximum SST and the upper and bottom white dashed curves in a indicate the axes of the minimum SST. The middle white dashed curve in b-d indicates the axis of the maximum air temperature and the upper and bottom white dashed curves in b-d indicate the axes of the minimum air temperature

North Atlantic tripole SSTA pattern significantly affects the generation of the TP $V_{10}$ dipole pattern in spring via the NaET wave train.

Focusing on the month-to-month variations, Fig. 9 presents the composite difference fields of the $500 \mathrm{hPa}$ geopotential height between seven strong positive tripole SSTA years $(1986,1989,1999,2008,2009,2012$ and 2014) and six strong negative tripole SSTA years $(1981,1987,1988$, 1998,2010 and 2013). The criterion is \pm 0.75 standard deviations for the normalized time series of the March SSTI (red solid curve in Fig. 5g). The results confirm the existence of the NaET wave train in March (Fig. 9a), similar to the results for spring (Fig. 8a). However, the wave train is more zonal in April (Fig. 9b). The wavelength of the wave train in May (Fig. 9c) becomes smaller than that in March and April, which could be attributed to the significant change in the general circulation during May (Yasunari 1991; Lau and Yang 1997; Matsumoto 1997). The eastward shift in the NaET wave train is small from March to May, presenting a quasi-stationary pattern. Despite these month-to-month differences, it is evident that, associated with the persistent 
(a) SSTI vs Spring hgt $500 \mathrm{hPa}$

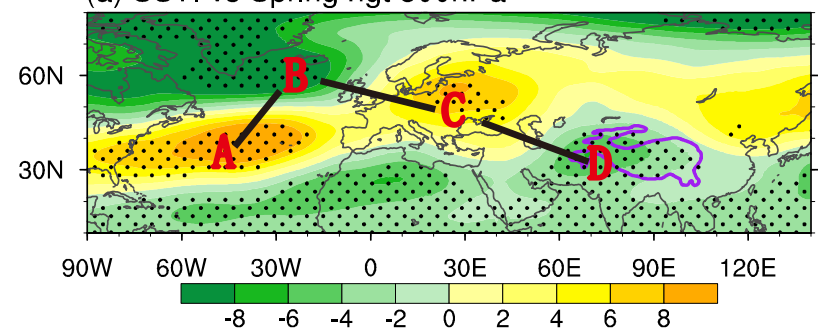

(c) SSTI vs Spring vorticity, wave flux $300 \mathrm{hPa}$

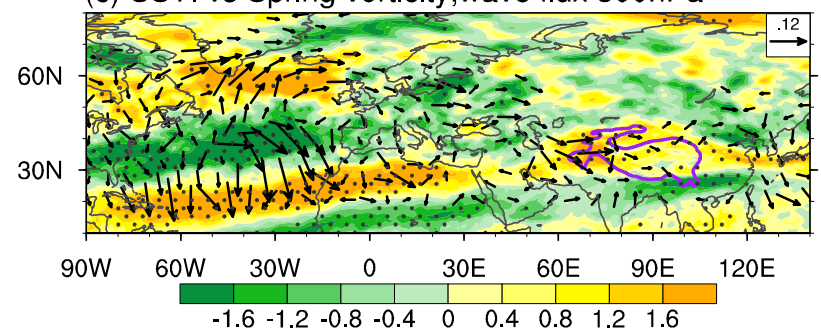

(d) SSTI vs Spring uv $500 \mathrm{hPa}$

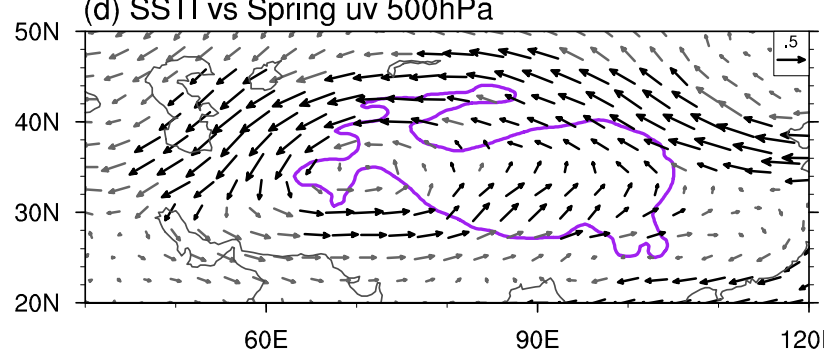

(b) SSTI vs Spring hgt

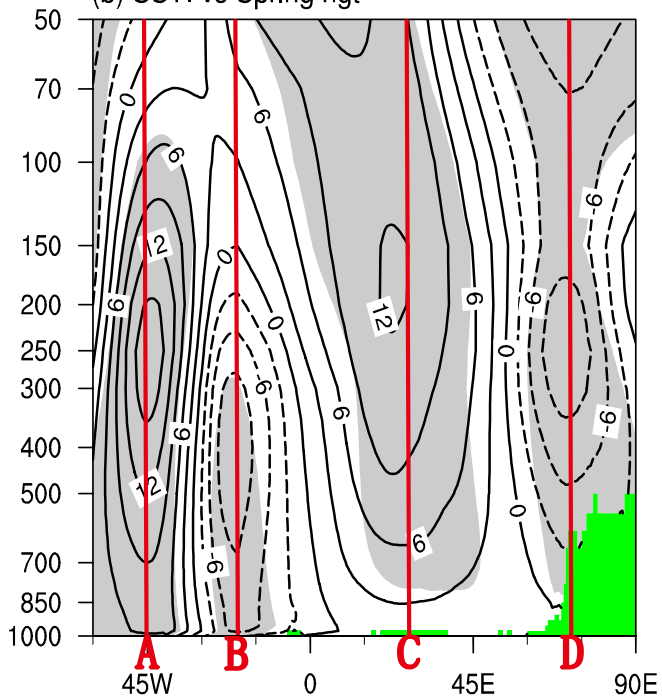

(e) SSTI vs Spring uv $10 \mathrm{~m}$

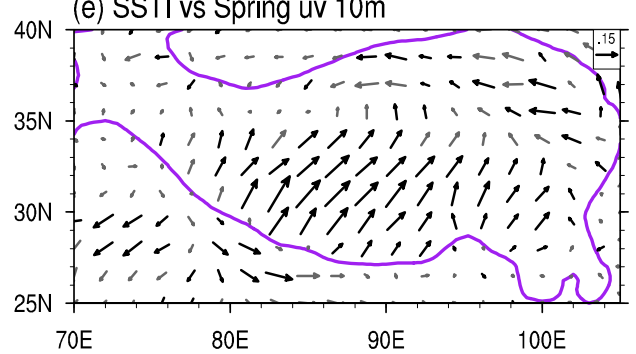

Fig. 8 Regression of spring quantities against the March SSTI during 1980-2014. a $500 \mathrm{hPa}$ geopotential height (gpm), where A, B, C and $\mathrm{D}$ represent the four centers of the wave train. $\mathbf{b}$ Zonal-vertical crosssection of geopotential height (contour interval $3 \mathrm{gpm}$ ) along the thick solid lines connecting A, B, C and D shown in (a). c $300 \mathrm{hPa}$ vorticity (shading, $10^{-6} \mathrm{~s}^{-1}$ ) and stationary wave activity flux (vectors, $\left.\mathrm{m}^{2} \mathrm{~s}^{-2}\right)$. d $500 \mathrm{hPa}$ wind $\left(\mathrm{m} \mathrm{s}^{-1}\right)$. e $10 \mathrm{~m}$ wind $\left(\mathrm{m} \mathrm{s}^{-1}\right)$. The

North Atlantic tripole SSTA pattern, a negative geopotential height anomaly center occurs in the western TP during the whole spring that corresponds to the $V_{10}$ dipole mode over the TP.

\subsection{Numerical experiments}

We further clarified these processes by conducting three AGCM experiments (CTRL, NA-POS and NA-NEG) based on FAMIL2. The experimental design is detailed in Table 1.

The control run (CTRL) experiment was an AMIP run using the monthly mean climatological SSTs averaged during 1980-2014 as the lower boundary conditions. The other external forcing fields (e.g., the greenhouse gases, aerosols, and volcanic and solar activity) were set as their climatological values. The CTRL experiment was integrated for 24 years. Only the last 20 years were utilized for the analysis. Two sets of SSTA sensitivity experiments were performed. Each set included 20 members integrated from January 1 to stippled areas in $\mathbf{a}, \mathbf{c}$ and the gray areas in $\mathbf{b}$ denote values exceeding the 95\% confidence level based on Student's $t$-test. The black (gray) vectors in $\mathbf{c}-\mathbf{e}$ indicate values that are significant (insignificant) at the $95 \%$ confidence level. The purple contours in a, c-e indicate the $2000 \mathrm{~m}$ topographic height. The green shading in $\mathbf{b}$ denotes the topography

May 31, with the initial fields taken from every January 1 of the last 20 years of the CTRL experiment. One of the SSTA sensitivity experiments was forced by the double-composite SSTA in the seven strong positive tripole SSTA years from January to May over the North Atlantic $\left(10^{\circ}-70^{\circ} \mathrm{N}, 100^{\circ}\right.$ $\mathrm{W}-10^{\circ} \mathrm{E}$ ), which is referred to as the NA-POS experiment. Another SSTA sensitivity experiment, NA-NEG, is the same as NA-POS, but forced by the prescribed strong negative tripole SSTA pattern with a double magnitude. The magnitude of the double positive (negative) composite SSTA is smaller (larger) than the maximum (minimum) SSTA that occurred in 2014 (2010) in the North Atlantic (Fig. 5g). Therefore it is acceptable to use the double observational SSTA in the North Atlantic as the SSTA in the sensitivity experiments. The differences between the NA-POS and NA-NEG ensemble means were evaluated to assess the impact of the North Atlantic tripole SSTA on circulation and climate.

Figure 10 illustrates the difference fields of geopotential height between the NA-POS and NA-NEG ensemble means. 
(a) Mar hgt $500 \mathrm{hPa}$

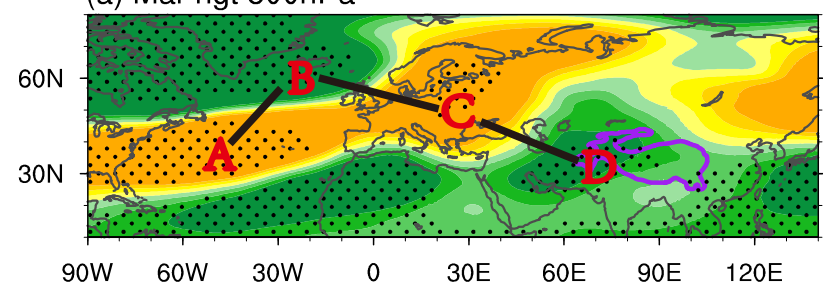

(b) Apr hgt $500 \mathrm{hPa}$

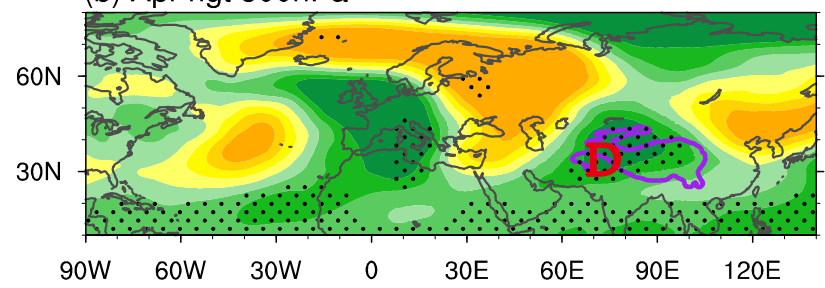

(c) May hgt $500 \mathrm{hPa}$

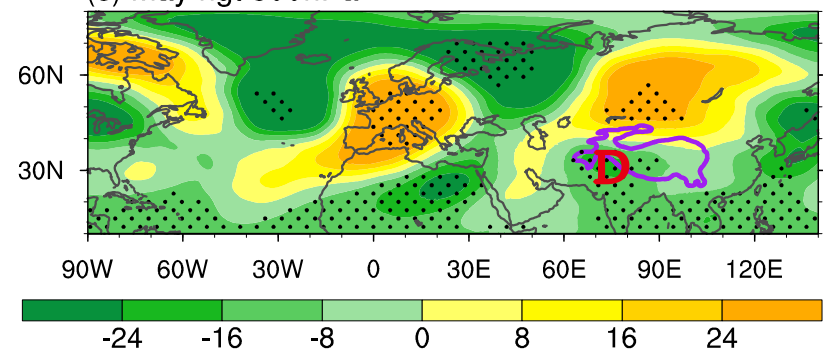

Fig. 9 Composite differences in the $500 \mathrm{hPa}$ geopotential height (gpm) between seven strong positive tripole SSTA years (SSTI greater than 0.75 standard deviations) and six strong negative tripole SSTA years (SSTI less than -0.75 standard deviations) in a March, b April, and c May. The stippled areas denote values exceeding the $95 \%$ confidence level based on Student's $t$-test. The purple contour indicates the $2000 \mathrm{~m}$ topographic height

The NaET wave train with four centers extending from the middle of the North Atlantic to the western TP in spring (Fig. 10a) is well simulated. The zonal-vertical cross-section of geopotential height also reveals an equivalent barotropic structure along the wave train in the troposphere (Fig. 10b). These results are consistent with the observed change in circulation owing to the tripole SSTA in the North Atlantic during spring (Fig. 8a, b). The observed and simulated quasi-stationary wave trains are similar in March (Figs. 9a, 10c). However, compared with the results based on observations in April and May (Fig. 9b, c), the evolution of the wave trains is slower in the sensitivity experiments (Fig. 10d, e). This might be because the sensitivity experiments only consider North Atlantic tripole SSTA forcing. Other extra forcings, such as air-sea interactions over the Atlantic Ocean in the AGCM are ignored. Despite this difference, the simulated and observed results both present a quasi-stationary wave train extending from the North Atlantic to the western TP in the mid- to upper troposphere that leads to a negative geopotential height anomaly center over the western TP during the whole spring, corresponding to the $V_{10}$ dipole pattern over the TP.

\section{Mechanisms linking the Tibetan Plateau forcing in spring to the seasonal transition over South Asia}

The above analyses signify that the winter-spring tripole SSTA pattern over North Atlantic is crucial to the occurrence of the spring $V_{10}$ dipole mode over the TP. We next explore the impacts of the $V_{10}$ dipole mode over the TP on surface heating and atmospheric circulation. Figure 11 presents the composite differences in $\mathrm{SH}$ and circulation over the TP and surrounding regions between nine strong positive $V_{10}$ dipole years $\left(\mathrm{V}_{10} \mathrm{I} 2\right.$ greater than 0.7 standard deviations in 1982, 1986, 1989, 1992, 1997, 2005, 2009, 2012 and 2014) and eight strong negative $V_{10}$ dipole years $\left(\mathrm{V}_{10} \mathrm{I} 2\right.$ less than -0.7 standard deviations in $1980,1984,1988,1990$, 2002, 2006, 2007 and 2010). The results are insensitive to the value of the standard deviation threshold, with \pm 0.7 chosen because it allows more composite members to be included.

Figure 11a-f shows the month-to-month evolution of the difference in geopotential height and vorticity along the zonal-vertical cross-section averaged between $30^{\circ}$ and $35^{\circ}$ $\mathrm{N}$. There is a baroclinic structure with a deep and strong negative geopotential height anomaly in the mid- to upper troposphere centered at $200 \mathrm{hPa}$, but a shallow and weak positive anomaly at lower levels over the western TP during

Table 1 Experimental design

\begin{tabular}{ll}
\hline Name & Description \\
\hline CTRL & AMIP run using the monthly mean climatological SSTs as the lower boundary conditions. The other forcing \\
& fields were prescribed as their climatological values. The experiment was integrated for 24 years and the \\
outputs of the last 20 years were used in the analysis \\
Climatological SSTs + prescribed strong positive tripole SSTA pattern with double magnitude over the North \\
Atlantic $\left(10^{\circ}-70^{\circ} \mathrm{N}, 100^{\circ} \mathrm{W}-10^{\circ} \mathrm{E}\right)$ from January 1 to May 31 . The simulations of 20 members integrated \\
from January 1 to May 31 with the initial fields taken from every January 1 of the last 20 years of the CTRL \\
experiment. The mean values from the 20 members were analyzed
\end{tabular}


March to May (Fig. 11a, c, e). The negative geopotential height anomaly in the mid- to upper troposphere is coordinated with the positive vorticity anomaly, whereas the positive geopotential height anomaly in the lower layer is coordinated with the negative vorticity anomaly (Fig. 11b, $\mathrm{d}, \mathrm{f}$ ). The slowly eastward shift in this baroclinic structure from March to May is similar to the NaET quasi-stationary wave train induced by NASST anomalies (Fig. 9a-c). This baroclinic structure in April and May based on $\mathrm{V}_{10} \mathrm{I} 2$ is also consistent with the regressed spring baroclinic structure at $\mathrm{D}$ (Fig. 8b) with a negative geopotential height anomaly above $850 \mathrm{hPa}$ and a positive anomaly below, although the positive anomaly in Fig. $8 \mathrm{~b}$ is shallower and closer to the surface. This implies that the baroclinic structure in geopotential height over the western TP based on $\mathrm{V}_{10} \mathrm{I} 2$ is significantly influenced by TP thermal forcing.

In spring, a negative geopotential height anomaly center at $500 \mathrm{hPa}$ appears over the western $\mathrm{TP}$, accompanied with a westerly anomaly over the southern TP and an easterly anomaly over the northern TP (Fig. 11g). Similar to the

\section{(a) Spring hgt $500 \mathrm{hPa}$}

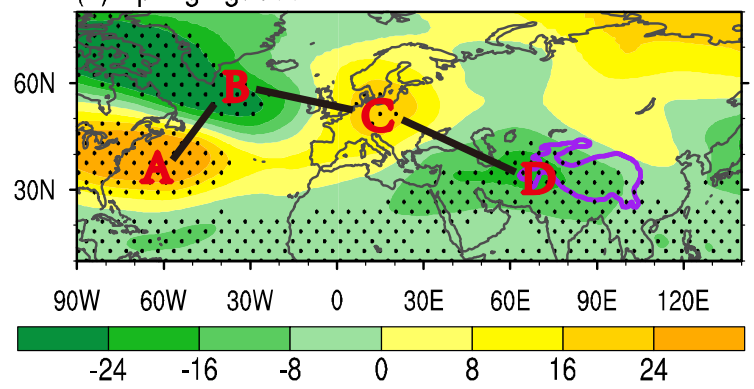

(b) Spring hgt

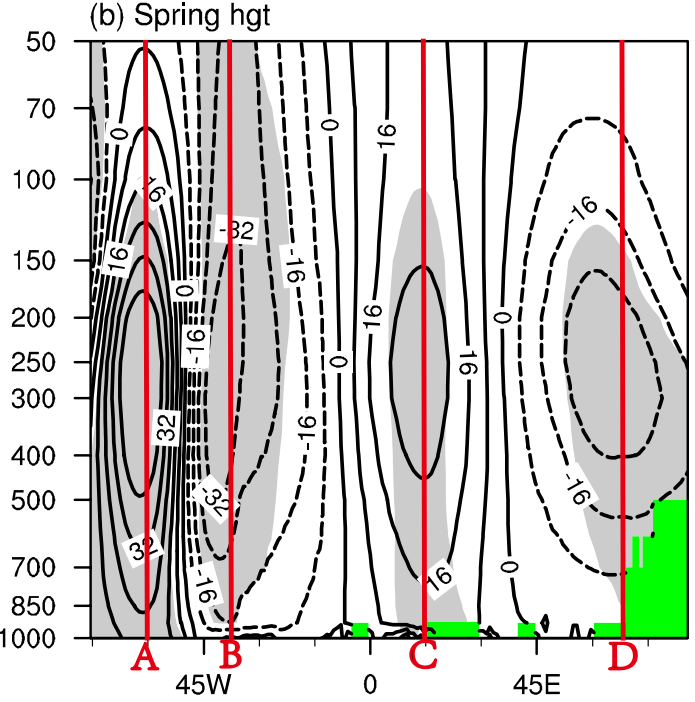

Fig. 10 Differences between the NA-POS and NA-NEG ensemble means. a Spring $500 \mathrm{hPa}$ geopotential height (gpm), where A, B, C and $\mathrm{D}$ represent the four centers of the wave train. b Spring zonalvertical cross-section of geopotential height (contour interval $8 \mathrm{gpm}$ ) along the thick solid lines connecting A, B, C and D shown in (a). composite $500 \mathrm{hPa}$ wind over the TP, the spring regression pattern of $V_{10}$ against $\mathrm{V}_{10} \mathrm{I} 2$ also shows a dipole mode over the TP with the regressed surface $S H$ increased in its southeast and decreased in its west and north during spring (Fig. 3c). In Sect. 4, we have demonstrated that the seasonal transition in the SASM and the associated precipitation over the SAS, BOB and the southwestern TP in May are closely related to the spring TP $V_{10}$ as well as $S H$ dipole modes. The composite differences in surface $S H$ and $V_{10}$ also show a dipole mode distribution over the TP in May (Fig. 11h), in agreement with the results for the spring period (Fig. 3c).

Previous studies revealed that a positive heating, either a source of condensation heating or surface $S H$, can stimulate an anticyclonic circulation with negative vorticity in the mid- to upper troposphere and a cyclonic circulation near the surface (Hoskins et al. 1985; Wu and Liu 2000; Liu et al. 2001; Wu et al. 2007). By contrast, a negative $S H$ anomaly near the surface can generate a vertical baroclinic structure with shallow anticyclonic circulation and positive geopotential height anomalies near the surface, but deep cyclonic

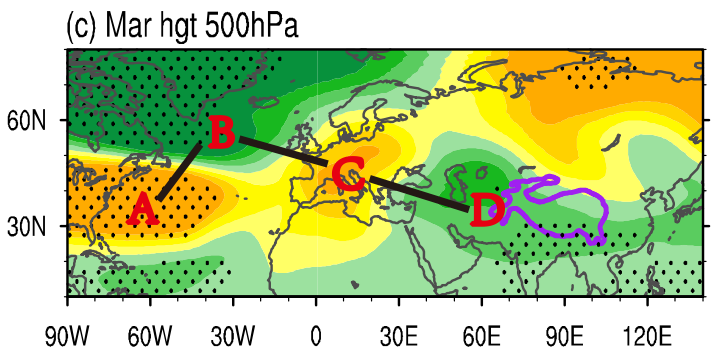

(d) Apr hgt $500 \mathrm{hPa}$

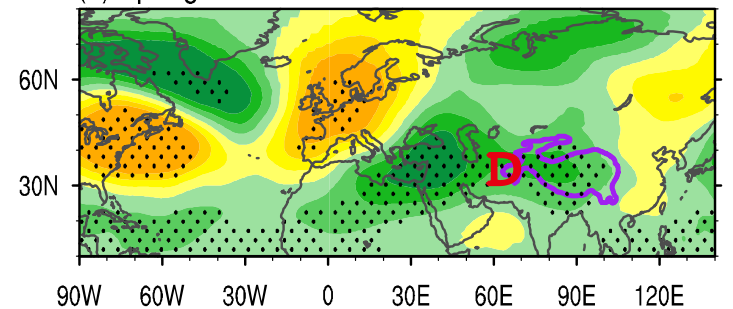

(e) May hgt $500 \mathrm{hPa}$

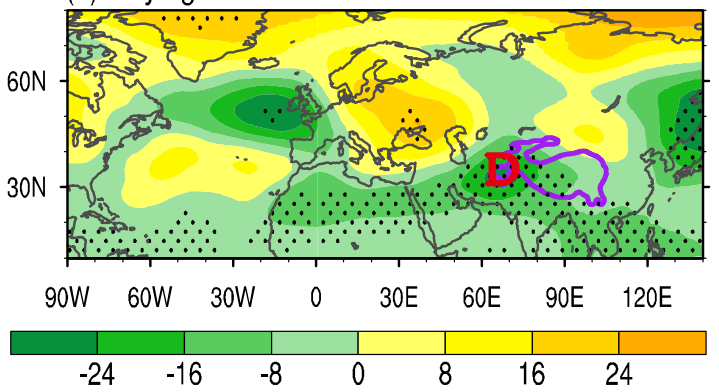

c-e $500 \mathrm{hPa}$ geopotential height (gpm) in March, April and May, respectively. The stippled areas in $\mathbf{a}, \mathbf{c}-\mathbf{e}$, and the gray areas in $\mathbf{b}$ denote values exceeding the $95 \%$ confidence level based on Student's $t$-test. The purple contours in a, $\mathbf{c}-\mathbf{e}$ indicate the $2000 \mathrm{~m}$ topographic height. The green shading in $\mathbf{b}$ denotes the topography 
(a) Mar hgt $(30-35 \mathrm{~N})$

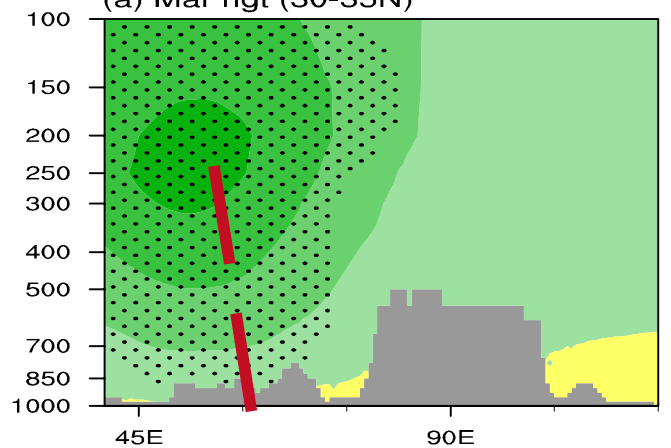

(c) Apr hg $(30-35 \mathrm{~N})$

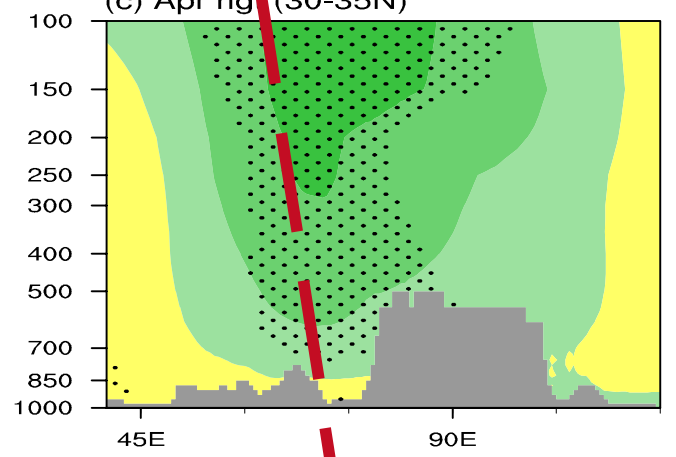

(e) May hgt $(3 \mathrm{C}-35 \mathrm{~N})$

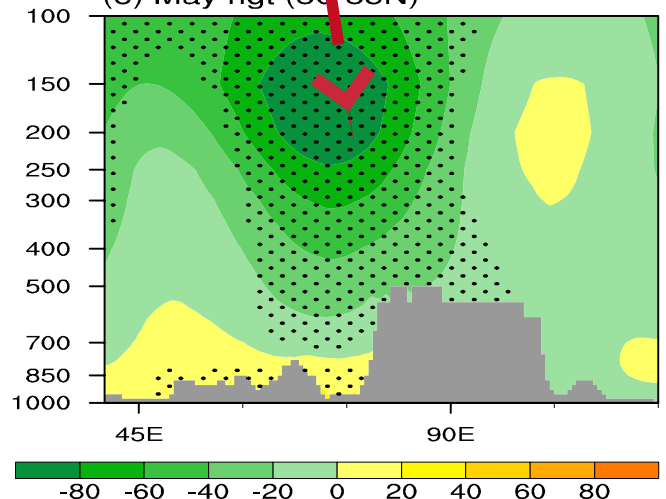

(g) Spring hgt,uv $500 \mathrm{hPa}$

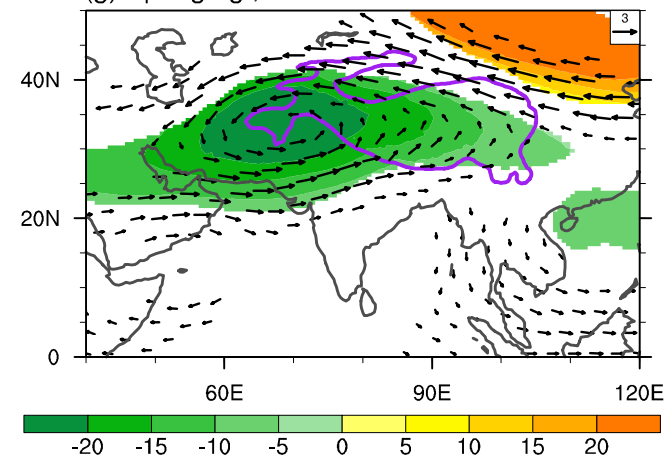

Fig. 11 Composite differences between nine strong positive Tibetan Plateau $10 \mathrm{~m}$ wind dipole years $\left(\mathrm{V}_{10} \mathrm{I} 2\right.$ greater than 0.7 standard deviations) and eight strong negative Tibetan Plateau $10 \mathrm{~m}$ wind dipole years $\left(\mathrm{V}_{10} \mathrm{I} 2\right.$ less than -0.7 standard deviations). Vertical cross-section of geopotential height (gpm) averaged between $30^{\circ}$ and $35^{\circ} \mathrm{N}$ in a March, c April, and e May. Vertical cross-section of vorticity $\left(10^{-5} \mathrm{~s}^{-1}\right)$ averaged between $30^{\circ}$ and $35^{\circ} \mathrm{N}$ in b March, $\mathbf{d}$ April, and $\mathbf{f}$ (b) Mar vorticity $(30-35 \mathrm{~N})$

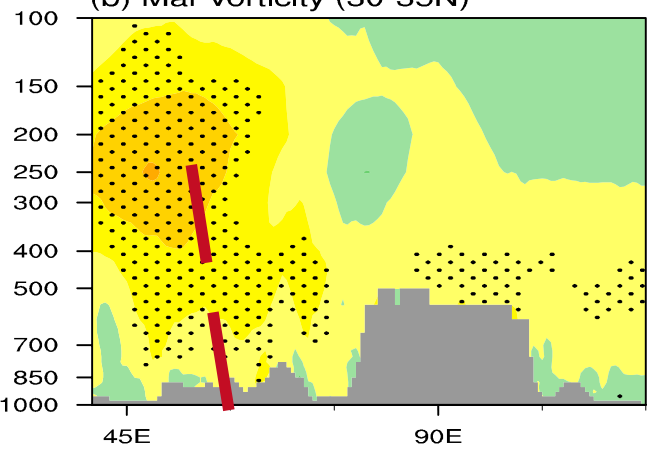

(d) Apr vorticity $(30-35 \mathrm{~N})$

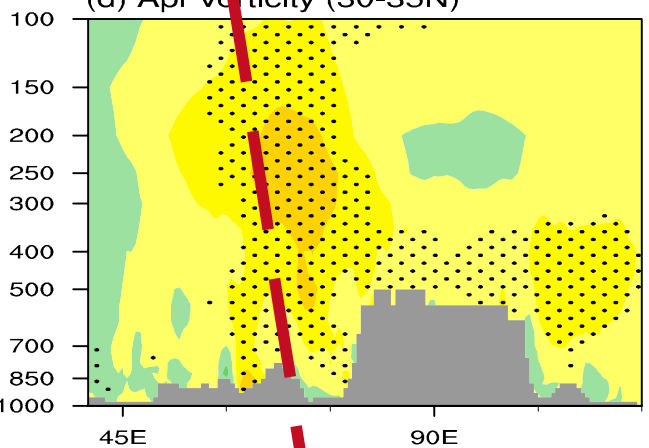

(f) May vorticit $(30-35 \mathrm{~N})$

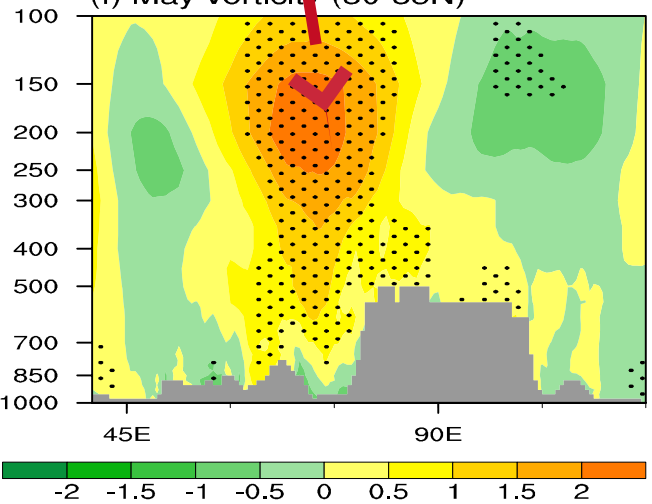

(h) May SH,uv $10 \mathrm{~m}$

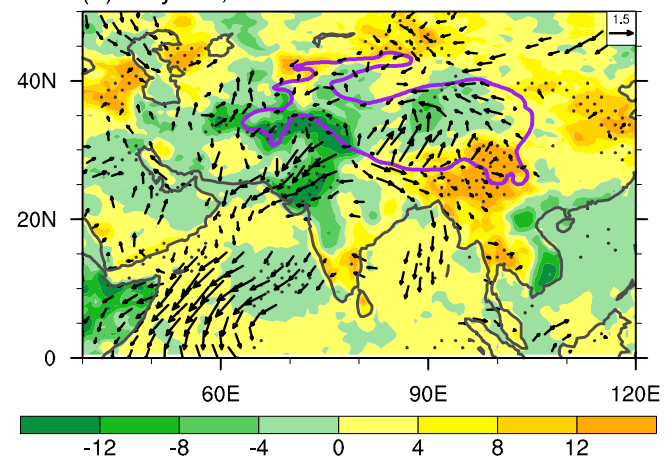

May. g Spring $500 \mathrm{hPa}$ geopotential height (shading, gpm) and wind (vectors, $\mathrm{m} \mathrm{s}^{-1}$ ). $\mathbf{h}$ May surface sensible heating (shading, $\mathrm{W} \mathrm{m}^{-2}$ ) and $10 \mathrm{~m}$ wind (vectors, $\mathrm{m} \mathrm{s}^{-1}$ ). The stippled areas in $\mathbf{a}-\mathbf{f}$ and $\mathbf{h}$, the shading in $\mathbf{g}$, and the black vectors in $\mathbf{g}, \mathbf{h}$ denote values exceeding the $95 \%$ confidence level based on Student's $t$-test. The gray shading in $\mathbf{a}-\mathbf{f}$ denotes the topography. The purple contours in $\mathbf{g}, \mathbf{h}$ indicate the $2000 \mathrm{~m}$ topographic height 
circulation and negative geopotential height anomalies in the mid- to upper troposphere. Accordingly, the difference in circulation shown in Fig. 11e-f can be attributed at least partly to a negative anomaly in surface $S H$ over the western $\mathrm{TP}$ and northwestern India (Fig. 11h).

In return, the surface $S H$ can also be influenced by the atmospheric circulation (Duan and Wu 2009; Liu et al.

(a) May omega $500 \mathrm{hPa}$

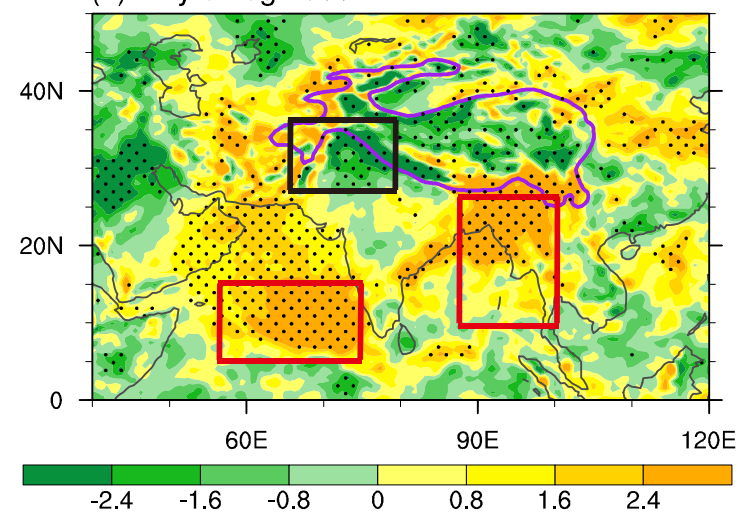

(c) May precip

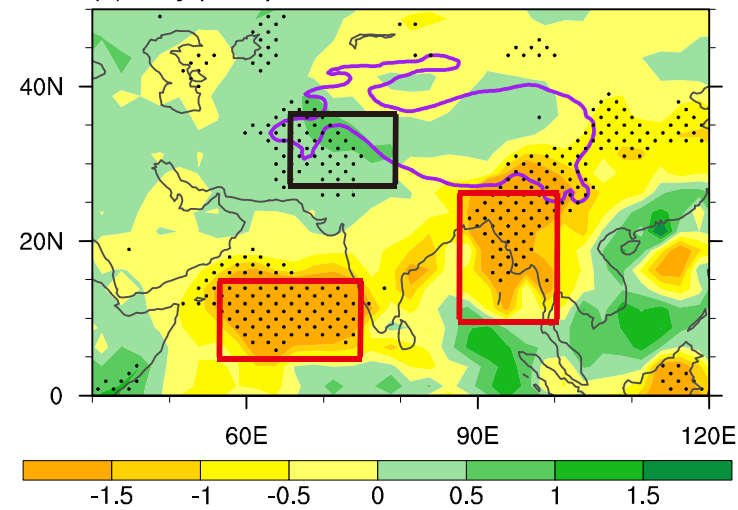

(e) May hgt,uv $200 \mathrm{hPa}$

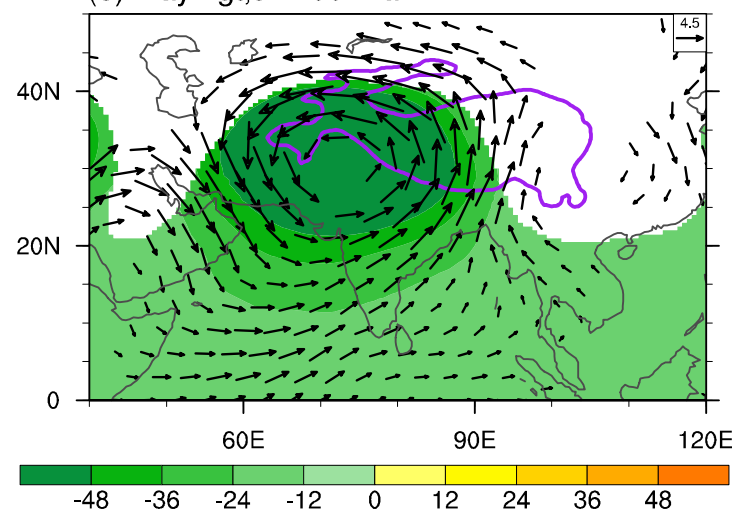

Fig. 12 Composite differences between the strong positive and strong negative Tibetan Plateau $10 \mathrm{~m}$ wind dipole years in May. a $500 \mathrm{hPa}$ vertical velocity $\left(10^{-2} \mathrm{~Pa} \mathrm{~s}^{-1}\right)$. b Vertically integrated water vapor flux from 700 to $500 \mathrm{hPa}$ (vectors, $\mathrm{kg} \mathrm{m}^{-1} \mathrm{~s}^{-1}$ ) and its divergence (shading, $10^{-5} \mathrm{~kg} \mathrm{~m}^{-2} \mathrm{~s}^{-1}$ ). $\mathbf{c}$ Precipitation $\left(\mathrm{mm} \mathrm{day}^{-1}\right.$ ). d Land-air temperature difference $\left({ }^{\circ} \mathrm{C}\right)$. e $200 \mathrm{hPa}$ geopotential height (shading,
2012). A reduction in $V_{10}$ or $\left(T_{\mathrm{s}}-T_{\mathrm{a}}\right)$ can decrease the surface $S H$ according to Eq. (1) and an increase in precipitation can decrease the local $S H$ by decreasing $T_{\mathrm{s}}$ and $\left(T_{\mathrm{s}}-T_{\mathrm{a}}\right)$. As the southwesterly flow of the anomalous cyclone above $700 \mathrm{hPa}$ over the southwestern TP (Fig. 11e, g) is forced to glide upwards along the mountain slope, an abnormal ascent of air develops over the southwestern TP (Fig. 12a).

\section{(b) May qflux,qflux_div}

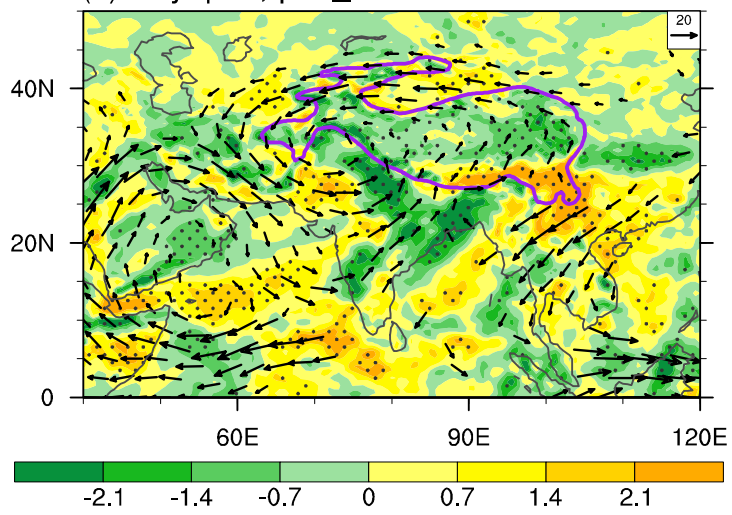

(d) May Ts-Ta

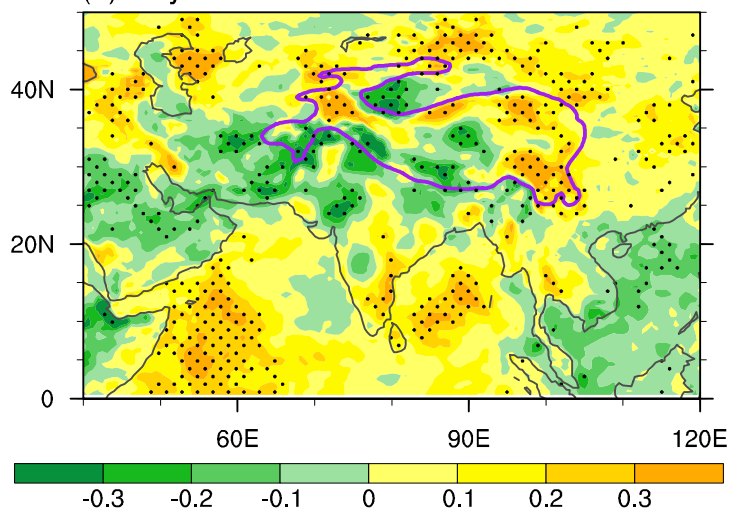

(f) May hgt,uv $850 \mathrm{hPa}$

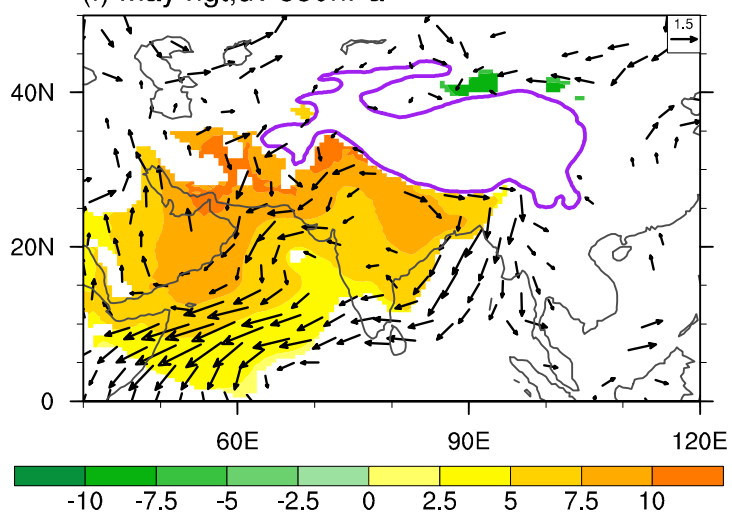

gpm) and wind (vectors, $\mathrm{m} \mathrm{s}^{-1}$ ). f $850 \mathrm{hPa}$ geopotential height (shading, gpm) and wind (vectors, $\mathrm{m} \mathrm{s}^{-1}$ ). The three boxes in $\mathbf{a}, \mathbf{c}$ are the same with Fig. 1d. The stippled areas in $\mathbf{a}-\mathbf{d}$, the shading in $\mathbf{e}, \mathbf{f}$, and the black vectors in $\mathbf{b}, \mathbf{e}, \mathbf{f}$ denote values exceeding the $95 \%$ confidence level based on Student's $t$-test. The purple contour indicates the $2000 \mathrm{~m}$ topographic height 
This anomalous southwesterly flow brings abundant water vapor from Arabian Sea to the southwestern TP, resulting in the local convergence of the water vapor flux (Fig. 12b) and an increase in precipitation over the southwestern TP (Fig. 12c). The increased precipitation there then decreases $T_{\mathrm{s}}$ as well as $\left(T_{\mathrm{s}}-T_{\mathrm{a}}\right)$ (Fig. 12d) over the southwestern TP and northwestern India, which leads to a reduction in surface $S H$ over these regions (Fig. 11h). It is clear that, over the western TP and northwestern India, there is a positive feedback among the negative $\mathrm{SH}$ anomaly, the positive precipitation anomaly and the baroclinic structure with an anomalous cyclonic low in the mid- to upper troposphere (Fig. 12e) and an anticyclonic high at lower levels (Fig. 12f).

An abnormal westerly flow over the tropical SAS and BOB at upper levels (Fig. 12e) is the opposite of the climate mean easterly flow (Figure not shown), which delays the westward development of the SAH in May. At the same time, an abnormal northeasterly flow develops from the southeastern TP to the SAS at lower levels (Fig. 12f), which is opposite to the in-situ climate mean southwesterly flow and the cross-equatorial Somali jet (Fig. 1b). Subsequently, less water vapor is transported to the SAS and BOB regions and a negative precipitation anomaly occurs in these areas (Fig. 12c).

In a word, the above diagnosis demonstrates that the anomalous positive dipole mode of the surface wind and $\mathrm{SH}$ over the TP in spring can delay the seasonal advance of the SAH in the upper troposphere and the cross-equatorial Somali jet in the lower layer, leading to a delay in the seasonal transition over South Asia.

From the transient-state geostrophic vorticity equation and the continuity equation, the vertical velocity can be simplified as:

$\omega \approx-\frac{\beta \partial v}{f \partial z}$

$\omega, v$ and $\beta$ are the transient vertical velocity, transient meridional wind and the meridional gradient of the Coriolis parameter, respectively (Wu and Liu 2000; Wu et al. 2015). Thus the anomalous southerly wind at $200 \mathrm{hPa}$ (Fig. 12e) and the northerly wind at $850 \mathrm{hPa}$ and near the surface (Figs. 11h, 12f) in the areas from the southeastern TP to the northern BOB and over the eastern Arabian Sea can lead to descending motion and a negative precipitation anomaly in-situ (Fig. 12a, c). The reduction in precipitation over the southeastern TP then enhances the local $S H$ and helps to maintain the $S H$ dipole mode over the TP (Fig. 11h). Moreover, the reduced precipitation over the BOB and Arabian Sea can lead to the negative diabatic heating anomalies insitu. Following the theory of Gill (1980), these negative diabatic heating anomalies contribute to the formation of the near-surface anomalous anticyclone to their west just over the India and Arabian Peninsula (Fig. 12f). Therefore, the reduced precipitation over the BOB and Arabian Sea and the negative $S H$ anomaly over the southwestern TP together contributes to the near-surface anomalous anticyclone over the southwest of the TP.

\section{Conclusion and discussion}

The seasonal transition in spring over South Asia shows a clear interannual variation, although it is unclear how the TP forcing and the North Atlantic SST contribute to this variation. Based on the observational analysis and numerical simulations, we find that the dipole modes of $S H$ and $V_{10}$ over the TP in spring are influenced by the winter-spring North Atlantic tripole SSTA pattern. These dipole modes are crucial to the seasonal transition of the SASM and the associated circulation and precipitation over the SAS, BOB and southwestern TP.

The relevant physical mechanisms can be summarized as follows. The tripole SSTA pattern in the North Atlantic features as a warm core in the middle and two cold cores in the subtropics and subpolar regions. This tripole SSTA pattern is closely coupled with the NAO in winter and can persist into the late spring. Observational analysis shows that the NAO coupled mode in winter and spring can remotely influence circulation and precipitation over South Asia when the TP forcing is included. The remote influence becomes trivial without TP forcing and therefore TP forcing plays a relaying role in this remote influence. This is because a positive winter-spring tripole SSTA pattern in the North Atlantic can trigger a quasi-stationary wave train, which extends from the North Atlantic to the western TP in the mid- to upper troposphere with cyclonic circulation above the western TP. Thus a spring $V_{10}$ dipole mode with a southwesterly (easterly) anomaly appears over the southern (northern) TP. This is evident in both the observations and numerical sensitivity experiments and is accompanied by a dipole mode of surface $\mathrm{SH}$ with a positive sign in the southeastern TP and a negative sign in the western and northern TP.

The cyclone above the western TP generates an abnormal southwesterly airflow, which is forced to glide upwards in the mid-troposphere along the mountain slope and forms an ascending motion over the southwestern TP. The southwesterly airflow brings sufficient water vapor from the Arabian Sea to the southwestern TP, leading to a local increase in precipitation. Hence a positive precipitation anomaly and a negative land-air temperature difference anomaly appear in the southwestern TP, resulting in a negative surface $S H$ anomaly. Such a negative surface $S H$ source leads to a baroclinic circulation structure with an anomalous cyclone in the 
mid- to upper troposphere and a shallow anticyclone at lower levels over the southwestern TP. Therefore, a positive feedback is established between the negative $S H$ anomaly, the positive precipitation anomaly and the baroclinic structure in the general circulation, with cyclonic circulation in the mid- to upper troposphere and anticyclonic circulation in the lower troposphere over the southwestern TP in May. Such circulation responses over the TP generate an anticyclonic circulation to the southwest of the TP in the lower troposphere. Thus, the anomalous northeasterly flow is appeared over the western Arabian Sea, which is in the opposite direction to the climate mean flow there, leading to the weakening of the cross-equatorial Somali jet and a delay in the seasonal transition over South Asia. Consequently, less water vapor is transported to the SAS and BOB regions and negative precipitation anomalies occur over there. In summary, the North Atlantic tripole SSTA pattern during winter-spring can delay the seasonal transition of the SASM and affect the associated circulation and precipitation over South Asia due to the modulation by TP forcing in spring.

The interannual variation of the seasonal transition and the associated precipitation in spring over South Asia is complex. It is influenced not only by tropical signals (e.g., the ENSO, the local SST and the SAH), but also by midlatitude factors (e.g., TP forcing and the NAO). Understanding the extent to which these factors synthetically contribute to the seasonal transition of the monsoon circulation and the associated precipitation anomaly over South Asia is crucial in climate prediction and requires further study.

Acknowledgements This work was jointly supported by the Strategic Priority Research Program of Chinese Academy of Sciences (Grant XDB40030204), the National Natural Science Foundation of China (Grants 91637312, 91937302 and 41730963) and the SOA Program on Global Change and Air-Sea Interactions (Grant GASI-IPOVAI-03).

Author contributions YL, GW and WY contributed to the study conception and design. Material preparation and data collection were performed by WY. Analysis was performed by WY, YL, X-QY, and GW. $\mathrm{BH}, \mathrm{JL}$, and $\mathrm{QB}$ contributed to the numerical experiment design. The first draft of the manuscript was written by WY and all authors commented on previous versions of the manuscript. All authors read and approved the final manuscript.

\section{Compliance with ethical standards}

Conflict of interest The authors declare that they have no conflict of interest.

Open Access This article is licensed under a Creative Commons Attribution 4.0 International License, which permits use, sharing, adaptation, distribution and reproduction in any medium or format, as long as you give appropriate credit to the original author(s) and the source, provide a link to the Creative Commons licence, and indicate if changes were made. The images or other third party material in this article are included in the article's Creative Commons licence, unless indicated otherwise in a credit line to the material. If material is not included in the article's Creative Commons licence and your intended use is not permitted by statutory regulation or exceeds the permitted use, you will need to obtain permission directly from the copyright holder. To view a copy of this licence, visit http://creativecommons.org/licenses/by/4.0/.

\section{References}

Adler RF, Huffman GJ, Chang A et al (2003) The version-2 global precipitation climatology project (GPCP) monthly precipitation analysis (1979-present). J Hydrometeorol 4(6):1147-1167. https://doi.org/10.1175/1525-7541(2003)004\%3c1147:tvgpc $\mathrm{p} \% 3 \mathrm{e} 2.0 . \mathrm{co} ; 2$

Bao Q, Wu XF, Li JX et al (2019) Outlook for El Niño and the Indian Ocean Dipole in autumn-winter 2018-2019. Chin Sci Bull 64(1):73-78. https://doi.org/10.1360/N972018-00913

Bretherton CS, Widmann M, Dymnikov VP et al (1999) The effective number of spatial degrees of freedom of a time-varying field. J Clim 12(7):1990-2009. https://doi.org/10.1175/15200442(1999)012\%3c1990:Tenosd\%3e2.0.Co;2

Cayan DR (1992a) Latent and sensible heat flux anomalies over the Northern Oceans: the connection to monthly atmospheric circulation. J Clim 5(4):354-369. https://doi.org/10.1175/15200442(1992)005\%3c0354:lashfa\%3e2.0.co;2

Cayan DR (1992b) Latent and sensible heat flux anomalies over the Northern Oceans: driving the sea surface temperature. J Phys Oceanogr 22(8):859-881. https://doi.org/10.1175/15200485(1992)022\%3c0859:lashfa\%3e2.0.co;2

Chen Y, Ding YH, Xiao ZN et al (2006) The impact of water vapor transport on the summer monsoon onset and abnormal rainfall over Yunnan Province in May. Chin J Atmos Scis 30(1):25-37

Chen L, Pryor SC, Wang H et al (2019) Distribution and variation of the surface sensible heat flux over the central and eastern Tibetan Plateau: comparison of station observations and multireanalysis products. J Geophys Res Atmos 124(12):6191-6206. https://doi. org/10.1029/2018jd030069

Cui YF, Duan AM, Liu YM et al (2015) Interannual variability of the spring atmospheric heat source over the Tibetan Plateau forced by the North Atlantic SSTA. Clim Dyn 45(5-6):1617-1634. https ://doi.org/10.1007/s00382-014-2417-9

Czaja A, Frankignoul C (2002) Observed impact of Atlantic SST anomalies on the North Atlantic oscillation. J Clim 15(6):606623. https://doi.org/10.1175/1520-0442(2002)015\%3c060 6:oioasa\%3e2.0.co;2

Dee DP, Uppala SM, Simmons AJ et al (2011) The ERA-Interim reanalysis: configuration and performance of the data assimilation system. Q J R Meteorol Soc 137(656):553-597. https:// doi.org/10.1002/qj.828

Deng MY, Lu RY, Chen W et al (2016) Interannual variability of precipitation in May over the South Asian monsoonal region. Int J Climatol 36(4):1724-1732. https://doi.org/10.1002/joc.4454

Deser C, Timlin MS (1997) Atmosphere-ocean interaction on weekly timescales in the North Atlantic and Pacific. J Clim 10(3):393408. https://doi.org/10.1175/1520-0442(1997)010\%3c039 3:aoiowt\%3e2.0.co;2

Ding YH, Chan JCL (2005) The East Asian summer monsoon: an overview. Meteorol Atmos Phys 89(1-4):117-142. https://doi. org/10.1007/s00703-005-0125-Z

Draper CS, Reichle RH, Koster RD (2018) Assessment of MERRA-2 land surface energy flux estimates. J Clim 31(2):671-691. https ://doi.org/10.1175/jcli-d-17-0121.1

Duan AM, Wu GX (2005) Role of the Tibetan Plateau thermal forcing in the summer climate patterns over subtropical Asia. Clim Dyn 24(7-8):793-807. https://doi.org/10.1007/s00382-004-0488-8 
Duan AM, Wu GX (2008) Weakening trend in the atmospheric heat source over the Tibetan plateau during recent decades. Part I: observations. J Clim 21(13):3149-3164. https://doi. org/10.1175/2007jcli1912.1

Duan AM, Wu GX (2009) Weakening trend in the atmospheric heat source over the Tibetan Plateau during recent decades. Part II: connection with climate warming. J Clim 22(15):4197-4212. https://doi.org/10.1175/2009jcli2699.1

Duan AM, Li F, Wang MR et al (2011) Persistent weakening trend in the spring sensible heat source over the Tibetan Plateau and its impact on the Asian summer monsoon. J Clim 24(21):56715682. https://doi.org/10.1175/jcli-d-11-00052.1

Duan AM, Sun RZ, He JH (2017) Impact of surface sensible heating over the Tibetan Plateau on the western Pacific subtropical high: a land-air-sea interaction perspective. Adv Atmos Sci 34(2):157168. https://doi.org/10.1007/s00376-016-6008-z

Gadgil S, Vinayachandran PN, Francis PA et al (2004) Extremes of the Indian summer monsoon rainfall, ENSO and equatorial Indian Ocean oscillation. Geophys Res Lett 31:L12213. https://doi. org/10.1029/2004GL019733

Gelaro R, McCarty W, Suarez MJ et al (2017) The modern-era retrospective analysis for research and applications, version 2 (MERRA-2). J Clim 30(14):5419-5454. https://doi.org/10.1175/ jcli-d-16-0758.1

Gill AE (1980) Some simple solutions for heat-induced tropical circulation. Q J R Meteorol Soc 106(449):447-462. https://doi. org/10.1256/smsqj. 44904

Goswami BN, Madhusoodanan MS, Neema CP et al (2006) A physical mechanism for North Atlantic SST influence on the Indian summer monsoon. Geophys Res Lett 33:L02706. https://doi. org $/ 10.1029 / 2005 \mathrm{gl} 024803$

Harris LM, Lin SJ (2014) Global-to-regional nested grid climate simulations in the GFDL high resolution atmospheric model. J Clim 27(13):4890-4910. https://doi.org/10.1175/jcli-d-13-00596.1

He SC, Yang J, Bao Q et al (2019) Fidelity of the observational/reanalysis datasets and global climate models in representation of extreme precipitation in East China. J Clim 32(1):195-212. https ://doi.org/10.1175/jcli-d-18-0104.1

Herceg-Bulić I, Kucharski F (2014) North Atlantic SSTs as a link between the wintertime NAO and the following spring climate. J Clim 27(1):186-201. https://doi.org/10.1175/jcli-d-12-00273.1

Hoskins BJ, McIntyre ME, Robertson AW (1985) On the use and significance of isentropic potential vorticity maps. Q J R Meteorol Soc 111(470):877-946. https://doi.org/10.1256/smsqj.47001

Hsu HH, Liu X (2003) Relationship between the Tibetan plateau heating and east Asian summer monsoon rainfall. Geophys Res Lett 30(20):2066. https://doi.org/10.1029/2003g1017909

Jiang XW, Li JP (2011) Influence of the annual cycle of sea surface temperature on the monsoon onset. J Geophys Res Atmos 116:D10105. https://doi.org/10.1029/2010jd015236

Kobayashi S, Ota Y, Harada Y et al (2015) The JRA-55 reanalysis: general specifications and basic characteristics. J Meteorol Soc Jpn 93(1):5-48. https://doi.org/10.2151/jmsj.2015-001

Lau WKM, Kim KM (2018) Impact of snow darkening by deposition of light-absorbing aerosols on snow cover in the himalayastibetan plateau and influence on the Asian summer monsoon: a possible mechanism for the blanford hypothesis. Atmosphere 9:438. https://doi.org/10.3390/atmos9110438

Lau KM, Yang S (1997) Climatology and interannual variability of the Southeast Asian summer monsoon. Adv Atmos Sci 14(2):141-162. https://doi.org/10.1007/s00376-997-0016-y

Li CF, Yanai M (1996) The onset and interannual variability of the Asian summer monsoon in relation to land sea thermal contrast. J Clim 9(2):358-375. https://doi.org/10.1175/15200442(1996)009\%3c0358:toaivo\%3e2.0.co;2
Li JP, Zhang L (2009) Wind onset and withdrawal of Asian summer monsoon and their simulated performance in AMIP models. Clim Dyn 32(7-8):935-968. https://doi.org/10.1007/s0038 2-008-0465-8

Li J, Yu RC, Zhou TJ et al (2005) Why is there an early spring cooling shift downstream of the Tibetan Plateau? J Clim 18(22):4660-4668. https://doi.org/10.1175/jcli3568.1

Li J, Yu RC, Zhou TJ (2008) Teleconnection between NAO and climate downstream of the Tibetan Plateau. J Clim 21(18):4680 4690. https://doi.org/10.1175/2008jcli2053.1

Li JX, Bao Q, Liu YM et al (2019) Evaluation of FAMIL2 in simulating the climatology and seasonal-to-interannual variability of tropical cyclone characteristics. J Adv Model Earth Syst 11:1117-1136. https://doi.org/10.1029/2018MS001506

Liang XY, Liu YM, Wu GX (2005) The role of land-sea distribution in the formation of the Asian summer monsoon. Geophys Res Lett 32:L03708. https://doi.org/10.1029/2004g1021587

Lin SJ (2004) A "vertically Lagrangian" finite-volume dynamical core for global models. Mon Weather Rev 132(10):2293-2307. https://doi.org/10.1175/1520-0493(2004)132\%3c2293:avlfd c\%3e2.0.co;2

Lin YL, Farley RD, Orville HD (1983) Bulk parameterization of the snow field in a cloud model. J Clim Appl Meteorol 22(6):10651092. https://doi.org/10.1175/1520-0450(1983)022\%3c106 5:bpotsf\%3e2.0.co;2

LinHo, Wang B (2002) The time-space structure of the Asian-Pacific summer monsoon: a fast annual cycle view. J Clim 15:20012019. https://doi.org/10.1175/1520-0442(2002)015

Liu YM, Wu GX, Liu H et al (2001) Condensation heating of the Asian summer monsoon and the subtropical anticyclone in the Eastern Hemisphere. Clim Dyn 17(4):327-338. https://doi. org/10.1007/s003820000117

Liu YM, Bao Q, Duan AM et al (2007) Recent progress in the impact of the Tibetan plateau on climate in China. Adv Atmos Sci 24(6):1060-1076. https://doi.org/10.1007/s00376-007-1060-3

Liu YM, Wu GX, Hong JL et al (2012) Revisiting Asian monsoon formation and change associated with Tibetan Plateau forcing: II. Change. Clim Dyn 39(5):1183-1195. https://doi. org/10.1007/s00382-012-1335-y

Liu C, Liu YM, Liu BQ (2015) Comparison of six sensible heat flux datasets over the Iranian-Tibetan Plateaus. J Meteorol Sci 35(4):398-404. https://doi.org/10.3969/2014jms.0038

Liu YM, Wang ZQ, Zhuo HF et al (2017) Two types of summertime heating over Asian large-scale orography and excitation of potential-vorticity forcing II. Sensible heating over TibetanIranian Plateau. Sci China Earth Sci 60(4):733-744. https:// doi.org/10.1007/s11430-016-9016-3

Liu YM, Lu MM, Yang HJ et al (2020) Land-atmosphere-ocean coupling associated with the Tibetan Plateau and its climate impacts. Natl Sci Rev 7:534-552. https://doi.org/10.1093/nsr/ nwaa011

Mao JY, Wu GX (2007) Interannual variability in the onset of the summer monsoon over the Eastern Bay of Bengal. Theor Appl Climatol 89(3-4):155-170. https://doi.org/10.1007/s0070 4-006-0265-1

Matsumoto J (1997) Seasonal transition of summer rainy season over Indochina and adjacent monsoon region. Adv Atmos Sci 14(2):231-245. https://doi.org/10.1007/s00376-997-0022-0

Pan LL (2005) Observed positive feedback between the NAO and the North Atlantic SSTA tripole. Geophys Res Lett 32:L06707. https://doi.org/10.1029/2005g1022427

Putman WM, Lin SH (2007) Finite-volume transport on various cubed-sphere grids. J Comput Phys 227(1):55-78. https://doi. org/10.1016/j.jcp.2007.07.022

Rayner NA, Parker DE, Horton EB et al (2003) Global analyses of sea surface temperature, sea ice, and night marine air 
temperature since the late nineteenth century. J Geophys Res Atmos 108(D14):4407. https://doi.org/10.1029/2002jd002670

Selkirk HB, Molod A, Pawson S et al. (2015) An assessment of upper tropospheric water vapor in the MERRA-2 reanalysis: comparisons with MLS and in situ water vapor measurements. Agu Fall Meeting

Shin CS, Huang BH (2016) Slow and fast annual cycles of the Asian summer monsoon in the NCEP CFSv2. Clim Dyn 47:529-553. https://doi.org/10.1007/s00382-015-2854-0

Shin CS, Huang BH, Zhu JS et al (2019) Improved seasonal predictive skill and enhanced predictability of the Asian summer monsoon rainfall following ENSO events in NCEP CFSv2 hindcasts. Clim Dyn 52:3079-3098. https://doi.org/10.1007/ s00382-018-4316-y

Smagorinsky J (1953) The dynamical influence of large scale heat sources and sinks on the quasi-stationary mean motions of the atmosphere. Q J R Meteorol Soc 79:342-366. https://doi. org/10.1002/qj.49707934103

Srivastava AK, Rajeevan M, Kulkarni R (2002) Teleconnection of OLR and SST anomalies over Atlantic Ocean with Indian summer monsoon. Geophys Res Lett 29(8):1284. https://doi. org/10.1029/2001g1013837

Sun RZ, Duan AM, Chen LL et al (2019) Interannual variability of the north pacific mixed layer associated with the spring Tibetan Plateau thermal forcing. J Clim 32(11):3109-3130. https://doi. org/10.1175/jcli-d-18-0577.1

Takaya K, Nakamura H (2001) A formulation of a phase-independent wave-activity flux for stationary and migratory quasigeostrophic eddies on a zonally varying basic flow. J Atmos Sci 58(6):608-627. https://doi.org/10.1175/15200469(2001)058\%3c0608:afoapi\%3e2.0.co;2

Tamura T, Koike T (2010) Role of convective heating in the seasonal evolution of the Asian summer monsoon. J Geophys Res Atmos 115:D14103. https://doi.org/10.1029/2009jd013418

Wang B (1988) Dynamics of tropical low-frequency waves: an analysis of the moist Kelvin wave. J Atmos Sci 45(14):2051-2065. https://doi.org/10.1175/1520-0469(1988)045\%3c2051:dotlf $\mathrm{w} \% 3 \mathrm{e} 2.0 . \mathrm{co} ; 2$

Wang LJ, Guo SH (2012) Interannual variability of the South-Asian high establishment over the Indo-China Peninsula from April to May and its relation to Southern Asian summer monsoon. Trans Atmos Sci 35(1):10-23. https://doi.org/10.13878/j.cnki. dqkxxb.2012.01.010

Wang B, Li TM (1994) Convective interaction with boundarylayer dynamics in the development of a tropical intraseasonal system. J Atmos Sci 51(11):1386-1400. https://doi. org/10.1175/1520-0469(1994)051\%3c1386:ciwbld\%3e2.0.co;2

Wang B, LinHo (2002) Rainy season of the Asian-Pacifc summer monsoon. J Clim 15(4):386-398. https://doi.org/10.1175/15200442(2002)015\%3c0386:RSOTAP\%3e2.0.CO;2

Wang B, LinHo ZYS et al (2004) Definition of South China sea monsoon onset and commencement of the East Asia summer monsoon. J Clim 17(4):699-710. https://doi.org/10.1007/s0038 2-011-1059-4

Wang B, Bao Q, Hoskins B et al (2008) Tibetan plateau warming and precipitation changes in East Asia. Geophys Res Lett 35:L14702. https://doi.org/10.1029/2008g1034330

Wang B, Huang F, Wu ZW et al (2009) Multi-scale climate variability of the South China Sea monsoon: a review. Dyn Atmos Oceans 47(1-3):15-37. https://doi.org/10.1016/j.dynatmoce.2008.09.004

Wang B, Li J, He Q (2017) Variable and robust East Asian monsoon rainfall response to El Niño over the past 60 years (1957-2016). Adv Atmos Sci 34:1235-1248. https://doi.org/10.1007/s0037 6-017-7016-3

Wang ZB, Wu RG, Chen SF et al (2018) Influence of western Tibetan Plateau summer snow cover on east Asian summer rainfall. J Geophys Res Atmos 123(5):2371-2386. https://doi. org/10.1002/2017jd028016

Wang ZQ, Yang S, Lau NC et al (2018) Teleconnection between summer NAO and East China rainfall variations: a bridge effect of the Tibetan Plateau. J Clim 31(16):6433-6444. https://doi. org/10.1175/jcli-d-17-0413.1

Wang ZB, Wu RG, Zhao P et al (2019) Formation of snow cover anomalies over the Tibetan Plateau in cold seasons. J Geophys Res Atmos 124(9):4873-4890. https://doi.org/10.1029/2018jd029525

Watanabe M, Kimoto M (2000) Atmosphere-ocean thermal coupling in the North Atlantic: a positive feedback. Q J R Meteorol Soc 126(570):3343-3369. https://doi.org/10.1256/smsqj.57016

Webster PJ, Hoyos CD (2004) Prediction of monsoon rainfall and river discharge on 15-30-day time scales. Bull Am Meteorol Soc 85(11):1745-1765. https://doi.org/10.1175/Bams-85-11-1745

Webster PJ, Magana VO, Palmer TN et al (1998) Monsoons: processes, predictability, and the prospects for prediction. J Geophys Res Oceans 103(C7):14451-14510. https://doi.org/10.1029/97jc0 2719

Wu GX, Liu YM (2000) Thermal adaptation, overshooting, dispersion, and subtropical high. Part I: thermal adaptation and overshooting. Chin J Atmos Sci 24(4):433-436

Wu GX, Liu YM (2016) Impacts of the Tibetan Plateau on Asian climate. Meteorol Monogr 56:7.1-7.29. https://doi.org/10.1175/ amsmonographs-d-15-0018.1

Wu R, Wang B (2001) Multi-stage onset of the summer monsoon over the western North Pacific. Clim Dyn 17:277-289. https://doi. org/10.1007/s003820000118

Wu GX, Zhang YS (1998) Tibetan Plateau forcing and the timing of the monsoon onset over South Asia and the South China Sea. Mon Weather Rev 126(4):913-927. https://doi.org/10.1175/15200493(1998)126\%3c0913:tpfatt\%3e2.0.co;2

Wu GX, Liu H, Zhao YC et al (1996) A nine-layer atmospheric general circulation model and its performance. Adv Atmos Sci 13(1):18. https://doi.org/10.1007/BF02657024

Wu GX, Li WP, Guo H et al (1997) Sensible heat driven air-pump over the Tibetan Plateau and its impacts on the Asian summer monsoon. Collections on the memory of Zhao Jiuzhang. Chinese Science Press, Beijing, pp 116-126

Wu GX, Liu YM, Wang TM et al (2007) The influence of mechanical and thermal forcing by the Tibetan Plateau on Asian climate. J Hydrometeorol 8(4):770-789. https://doi.org/10.1175/jhm609.1

Wu GX, Guan Y, Liu YM et al (2012) Air-sea interaction and formation of the Asian summer monsoon onset vortex over the Bay of Bengal. Clim Dyn 38(1-2):261-279. https://doi.org/10.1007/ s00382-010-0978-9

Wu GX, Duan AM, Liu YM et al (2015) Tibetan Plateau climate dynamics: recent research progress and outlook. Natl Sci Rev 2(1):100-116. https://doi.org/10.1093/nsr/nwu045

Wu GX, Zhuo HF, Wang ZQ et al (2016) Two types of summertime heating over the Asian large-scale orography and excitation of potential-vorticity forcing I. Over Tibetan Plateau. Sci China Earth Sci 59(10):1996-2008. https://doi.org/10.1007/s1143 0-016-5328-2

Xiang BQ, Wang B (2013) Mechanisms for the advanced Asian summer monsoon onset since the mid-to-late 1990s. J Clim 26(6):1993-2009. https://doi.org/10.1175/jcli-d-12-00445.1

Xie SP, Hu KM, Hafner J et al (2009) Indian Ocean capacitor effect on Indo-Western Pacific climate during the summer following El Niño. J Clim 22:730-747. https://doi.org/10.1175/2008jcli2544.1

Yanai M, Wu GX (2006) Effects of the Tibetan Plateau. In: The Asian Monsoon. Springer Praxis Books, Springer, Berlin, Heidelberg, pp 513-549. https://doi.org/10.1007/3-540-37722-0_13

Yang K, Guo XF, Wu BY (2011) Recent trends in surface sensible heat flux on the Tibetan Plateau. Sci China Earth Sci 54(1):19-28. https://doi.org/10.1007/s11430-010-4036-6 
Yasunari T (1991) The monsoon year-a new concept of the climatic year in the tropics. Bull Am Meteorol Soc 72(9):1331-1338. https://doi.org/10.1175/1520-0477(1991)072\%3c1331:tmync o\%3e2.0.co;2

Yeh TC, Gao YX (1979) Meteorology of the Qinghai-Xizang (Tibet) Plateau. Chinese Science Press, Beijing, p 278

Yu RC, Zhou TJ (2004) Impacts of winter-NAO on March cooling trends over subtropical Eurasia continent in the recent half century. Geophys Res Lett 31:L12204. https://doi.org/10.1029/2004g 1019814

Yu WD, Shi JW, Liu L et al (2012) The onset of the monsoon over the Bay of Bengal: the observed common features for 20082011. Atmos Oceanic Sci Lett 5(4):314-318. https://doi. org/10.1080/16742834.2012.11447009

Yu JH, Liu YM, Ma TT et al (2018a) The influence of surface potential vorticity density forcing over the Tibetan Plateau in the 2008 winter storm. Part II: numerical simulation. Acta Meteorologica Sinica 76(6):887-903. https://doi.org/10.11676/qxxb2018.043

Yu W, Liu YM, Yang XQ et al (2018b) The interannual and decadal variation characteristics of the surface sensible heating at different elevations over the Qinghai-Tibetan Plateau and attribution analysis. Plateau Meteorol 37(5):1161-1176. https://doi. org/10.7522/j.issn.1000-0534.2018.00027

Zar JH (2010) Biostatistical analysis. Q Rev Biol 18:797-799
Zhang YY, Li ZX, Liu BQ (2015) Interannual variability of surface sensible heating over the Tibetan Plateau in boreal spring and its influence on the onset time of the Indian Summer monsoon. Chin J Atmos Sci 39(6):1059-1072. https://doi.org/10.3878/j. issn.1006-9895.1410.14226

Zhao P, Chen LX (2001) Climatic features of atmospheric heat source/ sink over the Qinghai-Xizang Plateau in 35 years and its relation to rainfall in China. Sci China Earth Sci 44(9):858-864. https:// doi.org/10.1007/bf02907098

Zhao Y, Duan AM, Wu GX (2018) Interannual variability of late-spring circulation and diabatic heating over the Tibetan Plateau associated with indian ocean forcing. Adv Atmos Sci 35(8):927-941. https://doi.org/10.1007/s00376-018-7217-4

Zheng F, Li JP, Li YJ et al (2016) Influence of the summer NAO on the spring-NAO-based predictability of the East Asian summer monsoon. J Appl Meteorol Climatol 55:1459-1476. https://doi. org/10.1175/jamc-d-15-0199.1

Zhu XY, Liu YM, Wu GX (2012) An assessment of summer sensible heat flux on the Tibetan Plateau from eight data sets. Sci China-Earth Sci 55(5):779-786. https://doi.org/10.1007/s1143 0-012-4379-2

Publisher's Note Springer Nature remains neutral with regard to jurisdictional claims in published maps and institutional affiliations. 